\title{
The Sulfidation of $\gamma$-Alumina and Titania Supported (Cobalt)Molybdenum Oxide Catalysts Monitored by EXAFS
}

\author{
R. G. L eliveld, ${ }^{1}$ A . J. van Dillen, J. W. Geus, and D. C. Koningsberger \\ D epartment of I norganic Chemistry, D ebye Institute, U trecht U niversity, P.O. B ox 80083, 3508 T B U trecht, The N etherlands \\ R eceived January 16, 1997; revised M arch 27, 1997; accepted M ay 30, 1997
}

\begin{abstract}
The sulfidation of $\gamma$-alumina- and titania-supported (cobalt)molybdenum oxide catalysts has been studied with $X$-ray absorption spectroscopy and temperature programmed sulfidation (TPS). The catalysts were stepwise sulfided at temperatures between 298 and $673 \mathrm{~K}$ and their structure was determined with EXAFS spectroscopy. On alumina oxygen- sulfur exchange starts at a temperature just above room temperature resulting in the formation of monomeric and dimeric molybdenum sulfide species containing disulfide ligands. Between 448 and $523 \mathrm{~K}$ the disulfide ligands are reduced with hydrogen and only dimeric molybdenum sulfide species with a Mo-Mo distance of 2.77 A remain. A bove $523 \mathrm{~K}$ these dimers aggregate to larger $\mathrm{MoS}_{2}$ particles. In contrast, on titania molybdenum oxide is sulfided to yield isolated molybdenum sulfide monomers at $523 \mathrm{~K}$, which similarly aggregate to $\mathrm{MoS}_{2}$ particles between 523 and $623 \mathrm{~K}$. No molybdenum sulfide dimers are observed as intermediates. Both on alumina and titania all intermediates are anchored to the support via $\mathrm{Mo}$ - 0 linkages with a bond distance of $2.0 \AA$. The addition of $\mathrm{Co}$ to $\mathrm{Mo} / \mathrm{Al}_{2} \mathrm{O}_{3}$ accelerates the rate of sulfidation, demonstrated by the TPS patterns. However, on titania a lowering of the sulfidation rate is observed next to the presence of molybdenum sulfide dimers, that are not present in the unpromoted catalyst. These observations can be ascribed to the presence of $\mathrm{COMOO}_{4}$ in the oxidic catalyst.

1997 Academic Press
\end{abstract}

\section{INTRODUCTION}

Supported transition metal catalysts like those of $\mathrm{Co}, \mathrm{Ni}$, and $\mathrm{M} O$ are applied in the hydrotreating of oil since the late 1920s. M any studies deal with the preparation and structure of these catalysts and the mechanism of hydrodesulfurisation (HDS), as reviewed by several authors (1-14). The active phase of these catalysts is assumed to consist of small $\mathrm{M} \mathrm{OS}_{2}$ platelets with $\mathrm{Co}$ or $\mathrm{Ni}$ promoter atoms decorating their edges. Originally proposed by Topsøe and coworkers (7), this so-called "CoM oS" model was confirmed by Bouwens et al. (15-17) and Crajé et al. $(18,19)$ by EXA FS and $M$ össbauer experiments. Industrially, fresh oxidic catalysts are activated by addition of compounds like $\mathrm{CS}_{2}$ or methylsulfides to the feedstock (20). In most laboratory

\footnotetext{
${ }^{1}$ A uthor for correspondence. E-mail: leliveld@chem.ruu.nl.
}

studies catalysts are sulfided by a mixture of $\mathrm{H}_{2} \mathrm{~S}$ and $\mathrm{H}_{2}$. It is very likely that the conversion of the oxidic catalyst structure into the sulfided phase determines the final structure and performance of the catalyst. D uring the last 15 years several studies were carried out on the mechanism of sulfidation of molybdenum oxide catalysts and possible structures of intermediates.

Extensive temperature programmed sulfidation (TPS) studies of (Co promoted) molybdenum oxide on alumina were performed by Moulijn and coworkers (21-23). They concluded that sulfidation initially takes place via an $0-S$ exchange reaction on $\mathrm{M} \mathrm{O}^{\mathrm{VI}}$. This exchange isfollowed by reduction of $\mathrm{M} \mathrm{O}^{\mathrm{VI}}$ by means of $\mathrm{S}$ elimination from the formed $\mathrm{M} 0 \mathrm{O}_{x} \mathrm{~S}_{y}$ compounds. The formed elemental sulfur reacts with hydrogen to $\mathrm{H}_{2} \mathrm{~S}$ in the temperature region from 430 to $600 \mathrm{~K}$. Schrader and Cheng (24) performed a stepwise sulfidation study of $\mathrm{Mo} / \mathrm{A} \mathrm{I}_{2} \mathrm{O}_{3}$ and identified with in situ laser $\mathrm{R}$ aman spectroscopy the presence of molybdenum oxysulfides and reduced molybdenum oxides during sulfidation. In another R aman study Payen et al. (25) also reported on oxysulfides as intermediates, but with $\mathrm{M}$ o reduced to $\mathrm{M} \mathrm{O}^{\mathrm{V}}$. A dditionally, they proposed sulfido compounds and $\mathrm{M} \mathrm{OS}_{3}$ as transient species. EXA FS studies of Parham and M erill (26) and Chiu et al. (27) on sulfidation of ( $\mathrm{Co}) \mathrm{M} \mathrm{o} / \mathrm{A} \mathrm{I}_{2} \mathrm{O}_{3}$ reported on $\mathrm{O}-\mathrm{S}$ exchange and subsequent formation and growth of $\mathrm{M} \mathrm{OS}_{2}$ slabs between 573 and $673 \mathrm{~K}$.

In a sulfidation study of $\mathrm{MoO}_{3} / \mathrm{SiO}_{2}$ de $\mathrm{B}$ oer et al. (28) found oxysulfides only to be present at low temperature. Characterisation with EXAFS of the catalyst sulfided at $423 \mathrm{~K}$ showed the presence of a molybdenum sulfide species, which structure resembled that of $\mathrm{M} \mathrm{OS}_{3}$. The $\mathrm{M} \mathrm{OS}_{3}$ particles are reduced with hydrogen to $\mathrm{M} \mathrm{OS}_{2}$ accompanied by the evolution of $\mathrm{H}_{2} \mathrm{~S}$ as observed by Scheffer et al. (21). In a recent sulfidation study of uncalcined $\mathrm{NiM}$ o/SiO 2 prepared with nitrilotriacetic acid (NTA) as chelating agent M edici found no bulk $\mathrm{M} \mathrm{OS}_{3}$ as intermediate, but small $\mathrm{M} \mathrm{OS}_{3}$ like clusters with a structure probably analogous to the $\left[\mathrm{M} \mathrm{O}_{2}\left(\mathrm{~S}_{2}\right)_{6}\right]^{2-}$ complex (29). For a complete transition from these clusters into $\mathrm{M} \mathrm{OS}_{2}$ the temperatures had to be raised above $583 \mathrm{~K}$. XPS studies by Niemandsverdriet and coworkers on $\mathrm{M} \mathrm{OO}_{3} / \mathrm{SiO}_{2} / \mathrm{Si}(100)$ model catalysts showed the 
presence of bridging disulfide ligands during sulfidation and substantial amounts of $\mathrm{M} \mathrm{O} \mathrm{O}^{\mathrm{V}}$ in an early stage of sulfidation $(30,31)$. These authors proposed the sulfidation mechanism to consist of an $\mathrm{O}-\mathrm{S}$ exchange followed by a M O-S redox process.

D espite all this work, there are still open questions. In a previous EXAFS study of sulfided molybdenum catalysts supported on alumina and titania we reported on the anchoring of molybdenum disulfide slabs to the support via M o-O bonds (32). However, the results of that study were not sufficient to draw conclusions about the origin or formation of the metalsulfide-support interaction during sulfidation. A dditionally, for the industrially used alumina catalysts an overview of the detailed structure of the intermediates during all stages of sulfidation is still lacking. For these reasons, the aim of this study was to retrieve detailed information about the structure of the catalyst during all stages of sulfidation and about the influence of the support. H ence, molybdenum oxide catalysts supported on alumina and titania were stepwise sulfided at temperatures between room temperature and $673 \mathrm{~K}$ and characterised with EXAFS. A dditionally, to study the influence of the promoter, catalysts containing both $\mathrm{C} 0$ and $\mathrm{M} O$ were prepared, sulfided at various temperatures and characterised. To provide a basisfor the interpretation of the EXA FS data, TPS patterns of the different catalysts were also recorded. Finally, intermediate structures present during the sulfidation of molybdenum oxide catalysts are proposed based both on our results and on available literature data.

\section{EXPERIMENTAL}

Preparation of the $C$ atalysts

A 15 wt $\% \mathrm{MoO}_{3} / \gamma-\mathrm{Al}_{2} \mathrm{O}_{3}$ and a 4.4 wt $\% \mathrm{MoO}_{3} / \mathrm{TiO}_{2}$ catalyst were prepared by incipient wetness impregnation of preshaped bodies (150-425 $\mu \mathrm{m}$ ) of $\gamma-\mathrm{Al}_{2} \mathrm{O}_{3}$ (K etjen CK 300 , specific surface area $200 \mathrm{~m}^{2} / \mathrm{g}$, pore volume $0.63 \mathrm{ml} / \mathrm{g}$ ) and $\mathrm{TiO}_{2}$ ( D egussa 7702 , specific surface area $44 \mathrm{~m}^{2} / \mathrm{g}$, pore volume $0.14 \mathrm{ml} / \mathrm{g}, 80 \%$ anatase), respectively, with an aqueous solution of $\left(\mathrm{NH}_{4}\right)_{6} \mathrm{M} \mathrm{O}_{7} \mathrm{O}_{24} \cdot 6 \mathrm{H}_{2} \mathrm{O}$ (M erck, p.a.) containing $25 \%$ ammonia. The surface coverage in both catalysts was $0.70 \mathrm{mg} \mathrm{Mo} / \mathrm{m}^{2}$. CoM o/A I $\mathrm{O}_{3}\left(3.8 \mathrm{wt} \% \mathrm{CO}_{3} \mathrm{O}_{4}\right.$, $14 \mathrm{wt} \% \mathrm{MoO}_{3}$ ) and $\mathrm{CoM}$ o/TiO 2 ( $1.1 \mathrm{wt} \% \mathrm{CO}_{3} \mathrm{O}_{4}, 4.3 \mathrm{wt} \%$ $\mathrm{MoO}_{3}$ ) with an equal $\mathrm{Co}: \mathrm{Mo}$ ratio were prepared by incipient wetness coimpregnation of $\gamma-\mathrm{A}_{2} \mathrm{O}_{3}$ and $\mathrm{TiO}_{2}$ with an aqueous solution containing the required amounts of $\left(\mathrm{NH}_{4}\right)_{6} \mathrm{M} \mathrm{O}_{7} \mathrm{O}_{24} \cdot 6 \mathrm{H}_{2} \mathrm{O}$ and $\mathrm{Co}\left(\mathrm{NO}_{3}\right)_{2} \cdot 6 \mathrm{H}_{2} \mathrm{O}$. A Il catalysts were subsequently dried with an air flow for $4 \mathrm{~h}$ at $298 \mathrm{~K}$, dried in static air at $383 \mathrm{~K}$ for $16 \mathrm{~h}$ and calcined in air at $723 \mathrm{~K}$ during $16 \mathrm{~h}$.

Temperature Programmed Sulfidation

Temperature-programmed sulfidation profiles were recorded in an automated microflow apparatus; $1 \mathrm{ml}$ of catalyst was put on a quartz filter in an quartz lab reactor $(8 \mathrm{~mm} \varnothing)$. O $\mathrm{n}$ top of the catalyst $1 \mathrm{ml}$ of quartz beads ( $1.5 \mathrm{~mm} \varnothing)$ was placed to ensure the gas mixture to reach oven temperature. Prior to reaction the reactor was flushed with $\mathrm{Ar}$ (flow rate $100 \mathrm{ml} / \mathrm{min}$ ) to remove air, where after the catalyst was exposed to a $100 \mathrm{ml} / \mathrm{min}$ flow of the sulfiding mixture of $\mathrm{H}_{2} \mathrm{~S} / \mathrm{H}_{2} / \mathrm{A} \mathrm{r}(10 / 40 / 50)$. A fter $30 \mathrm{~min}$ at room temperature the reactor temperature was linearly raised ( $5 \mathrm{~K} / \mathrm{min}$ ) to $673 \mathrm{~K}$. D uring sulfidation the $\mathrm{H}_{2} \mathrm{~S}$ concentration of the sulfidation mixture before and after the reactor was monitored with a U V N IS spectrophotometer (Varian, Q uartz cuvets $\mathrm{H}$ ellma, $20 \mathrm{~mm}$ ). The $\mathrm{H}_{2} \mathrm{~S}$ absorption was detected at $\lambda=232 \mathrm{~nm}$.

\section{EXAFS D ata Collection}

The EXAFS measurements were performed at EXAFS station 9.2 of the Wiggler beam line of the SR S at D aresbury (U.K.). The Si[220] double crystal monochromator was detuned to $50 \%$ intensity to minimise the presence of higher harmonics. The measurements were all carried out in transmission mode using optimised ion chambers as detectors. To minimise high and low frequency noise the counting time per data point varied from $1 \mathrm{~s}$ at $\mathrm{k}=3 \AA^{\circ-1}$ to $3 \mathrm{~s}$ at $\mathrm{k}=$ $20 \AA^{\circ}-1$ and at least three scans were recorded and averaged. A II spectra were recorded with the sample at liquid nitrogen temperature. The energy calibration of the monochromator was performed by means of a $\mathrm{M} 0$-foil. The absolute value of the M o-edge is 19,999 eV.

The catalyst samples were pressed into self-supporting wafers and mounted in an in situ EXAFS cell (33). The thickness of the wafer was chosen to give an absorbance $(\mu \mathrm{x})$ of 2.5 for optimal signal to noise ratio. To prevent selfabsorption for the high loaded $\mathrm{M} \mathrm{O} / \mathrm{A} \mathrm{I}_{2} \mathrm{O}_{3}$ and $\mathrm{CoM}$ o/A I $\mathrm{I}_{3}$ samples the thickness of the wafer was chosen to obtain a step in absorbance of 1.0 in the edge region $(\Delta \mu \mathrm{X}=1)$. The wafers were dried in situ at $393 \mathrm{~K}$ during $\mathrm{I} \mathrm{h}$ in a $\mathrm{He}$ flow (flow rate $50 \mathrm{ml} / \mathrm{min}$ ) to remove physisorbed water. The stepwise sulfidation of the catalysts was carried out in a $10 \%$ $\mathrm{H}_{2} \mathrm{~S} / \mathrm{H}_{2}$ flow during $30 \mathrm{~min}$ (flow rate $50 \mathrm{ml} / \mathrm{min}^{-1}$ ) at temperatures ranging from 298 to $673 \mathrm{~K}(5 \mathrm{~K} / \mathrm{min}$ linear heating rate). A fter sulfidation the samples were cooled down in $\mathrm{H}_{2} \mathrm{~S} / \mathrm{H}_{2}$ to room temperature $(10 \mathrm{~K} / \mathrm{min})$ and the cell was flushed for 15 min with $\mathrm{He}$ to remove $\mathrm{H}_{2} \mathrm{~S}$. The EXAFS spectrum was recorded after which the sample was allowed to reach room temperature again. Similarly the same sample was sulfided at a higher temperature in the given range and characterised with EXA FS.

\section{EXAFS D ata A nalysis}

Standard procedures were used to extract the EXAFS data from the measured absorption spectrum. The background was subtracted using cubic spline routines (34). N ormalisation was done by dividing the data by the height of the 
absorption edge at $50 \mathrm{eV}$. Phase shifts and backscattering amplitudes from reference compounds were used to calculate the EXA FS contributions: $\mathrm{N} \mathrm{a}_{2} \mathrm{M} \mathrm{OO}_{4}$ for the $\mathrm{M} \mathrm{O-O}$, and $\mathrm{MoS}_{2}$ for the Mo-S and Mo-Mo contributions. D etails of the references are described elsewhere (35). Phase shifts and backscattering amplitudes of the Mo-Al and M o-Ti contributions were theoretically calculated with the FEFF-3.1 code (36).

Multiple shell fitting of the EXAFS data was done in $\mathrm{R}$-space. The difference file technique was applied, together with phase-corrected Fourier transforms to resolve the different contributions (37). Coordination numbers were corrected for the difference in absorber-backscatterer distance between the reference compound and the unknown assuming an electron mean free path of $5 \AA^{\circ}$ (38).

The reliability of the calculated fit is usually expressed as the goodness of fit $\varepsilon_{v}^{2}$ which includes the statistical noise on the data (39). H owever, it proved that the random noise of the measured data is in some cases so low that $\varepsilon_{v}^{2} \gg 1$. In that case the noise is dominated by systematic errors from the measurement and data analysis. To correct the standard deviations of the structural parameters for the systematic errors, $\varepsilon_{v}^{2}$ should be corrected as described by Stern et al. (40). A Iternatively, we have chosen to express the quality of fit as the difference between the absolute or imaginary part of the Fourier transform of the experimental data with that of the model Fourier transform. These differences are described by the $\mathrm{FT}^{\mathrm{n}}$ variance:

$$
\mathrm{FT}^{n}=100 \frac{\int\left(\mathrm{FT}_{\text {model }}^{n}(R)-\mathrm{FT}_{\text {expt }}^{n}(R)\right)^{2}}{\int\left(\mathrm{FT}_{\text {expt }}^{n}(R)\right)^{2}}
$$

in which $\mathrm{n}$ represents the weight of the Fourier transform. The errors in the resulting fit parameters are estimated to be $20 \%$ in coordination number $\mathrm{N}, 1 \%$ in distance $\mathrm{R}, 10 \%$ in D ebye-Waller factor $\Delta \sigma^{2}$ and $10 \%$ in $\Delta \mathrm{E}_{0}$.

\section{RESULTS}

\section{Temperature Programmed Sulfidation}

Figure 1 represents the normalised $\mathrm{H}_{2} \mathrm{~S}$ absorption per $\mathrm{Mo}$ (no corrections were made for $\mathrm{Co}$ ) of the various catalysts versus the sulfidation temperature. I nitially, just above room temperature with all catalysts a positive peak due to desorption of physisorbed $\mathrm{H}_{2} \mathrm{~S}$ was observed. A t higher temperatures the catalysts started to consume $\mathrm{H}_{2} \mathrm{~S}$, followed by $\mathrm{a}_{2} \mathrm{~S}$ evolution peak at around $423-493 \mathrm{~K}$ in case of the alumina catalysts. B etween 493 and $673 \mathrm{~K}$ the alumina catalysts showed a further uptake of $\mathrm{H}_{2} \mathrm{~S}$. In contrast, the titania samples showed no $\mathrm{H}_{2} \mathrm{~S}$ production peak, but continuous absorption of $\mathrm{H}_{2} \mathrm{~S}$ in the range 293-673 K. Surprisingly, the normalised $\mathrm{H}_{2} \mathrm{~S}$ consumption per $\mathrm{Mo}$ atom is higher for the Mo catalysts in comparison with the $\mathrm{Co}_{0}$ promoted catalysts. Since the experimental setup was not
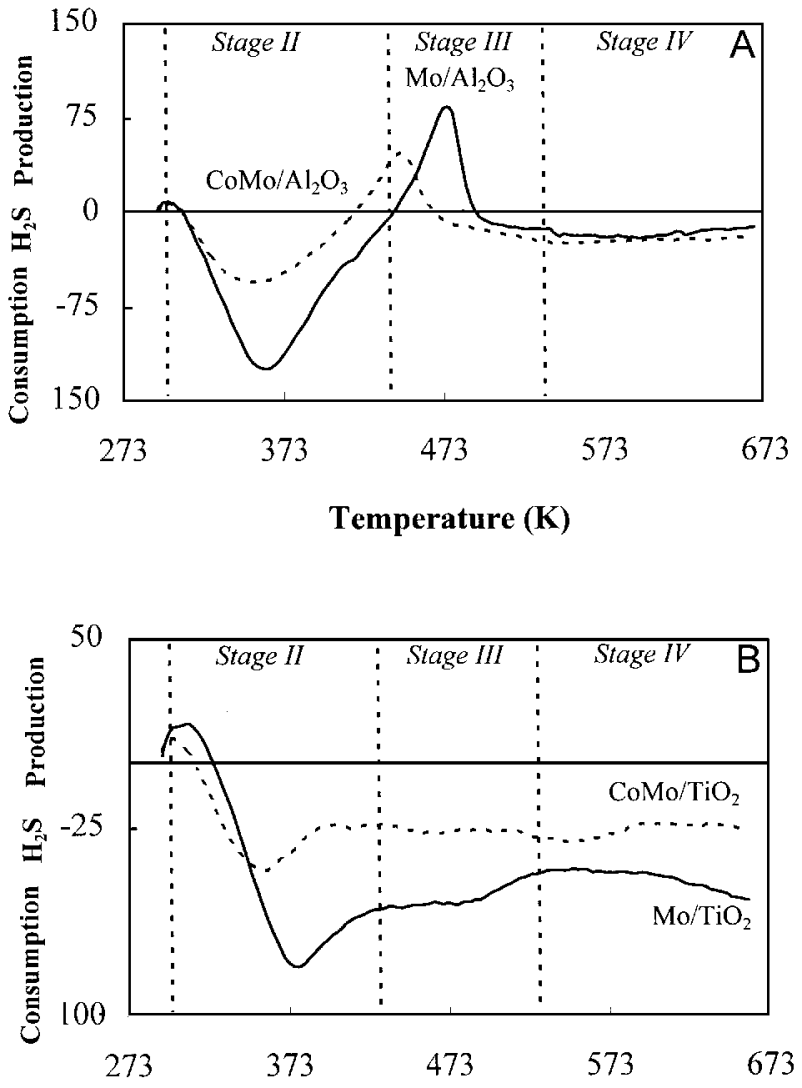

Temperature (K)

FIG. 1. TPS patterns of ( $\mathrm{A}$ ) $\mathrm{Mo} / \mathrm{Al}_{2} \mathrm{O}_{3}$ and $\mathrm{CoM} \mathrm{o} / \mathrm{Al}_{2} \mathrm{O}_{3}(\mathrm{~B}) \mathrm{Mo} / \mathrm{TiO}_{2}$ and $\mathrm{CoM} / \mathrm{TiO}_{2}$.

suited for quantitative analysis no further attempts were made to study this observation. Moreover, the main purpose of the TPS experiments was to provide a basis for the interpretation of the E X A FS data in terms of the consumption and production of $\mathrm{H}_{2} \mathrm{~S}$ by the catalysts as a function of the sulfidation temperature.

A ccordingly, the TPS pattern can roughly be divided in four temperature ranges as indicated in Fig. 1:

Stage I: sulfidation at $298 \mathrm{~K}$ (not shown)

Stage II : 298-448 K, uptake of $\mathrm{H}_{2} \mathrm{~S}$

Stage III : $448-523 \mathrm{~K}$, release of $\mathrm{H}_{2} \mathrm{~S}$ (for alumina catalysts)

Stage IV: $523-673 \mathrm{~K}$, (renewed) consumption of $\mathrm{H}_{2} \mathrm{~S}$.

On basis of these temperature ranges we decided to characterise the catalysts with EX A FS after sulfidation at $298 \mathrm{~K}$, at every $25 \mathrm{~K}$ in the region $363-523 \mathrm{~K}$ and after sulfidation at $673 \mathrm{~K}$.

In order to justify our approach of stepwise sulfidation and characterisation with EXAFS a modified sulfidation experiment was carried out. In this experiment the temperature was increased with steps of $25 \mathrm{~K}(5 \mathrm{~K} / \mathrm{min})$ and held 
constant at every temperature for $30 \mathrm{~min}$. It was observed that the UV-absorption dropped to the level of no $\mathrm{H}_{2} \mathrm{~S}$ consumption or production within a minute after stabilisation of the temperature. When the temperature was further raised the UV-absorption quickly returned to its former value before stabilising. These results indicated that the extent of sulfidation was solely determined by the temperature, which permitted a study of stepwise sulfidation and characterisation.

\section{N ear-E dge R egion}

The shape and position of the M o-K -absorption edge contains information about the valency and local symmetry of the $\mathrm{M} \mathrm{O}$ atom. Figure 2 presents the near-edge spectra of $\mathrm{Mo} / \mathrm{A} \mathrm{I}_{2} \mathrm{O}_{3}$ and $(\mathrm{Co}) \mathrm{Mo} / \mathrm{TiO}_{2}$ at different temperatures of sulfidation. The near-edge spectra of $\mathrm{CoM} \mathrm{o} / \mathrm{Al}_{2} \mathrm{O}_{3}$ were identical to tho se of $\mathrm{M} \mathrm{o} / \mathrm{A}_{2} \mathrm{O}_{3}$ and are therefore not shown. The spectra of both alumina and titania catalysts sulfided at room temperature contained a preedge peak that disappeared at higher temperatures. This preedge peak can be attributed to a 1s-4d bound state transition characteristic for $\mathrm{M} o$ atoms in an oxidic structure. The transition probability of this formally forbidden excitation is dependent on the local symmetry around the molybdenum atom. M ixing of metal $d$-states with ligand $p$-orbitals in case of a tetrahedral or nonperfect octahedral symmetry, as encountered in molybdenum oxides, gives rise to the observed preedge feature $(41,42)$. The absence of this preedge peak at higher sulfidation temperatures indicated transformation of the oxidic lattice into another (sulfidic) lattice.

A dditionally, the position of the absorption edge shifted to lower energy values at higher temperatures. The edgeposition of the samples sulfided at room temperature agreed with an oxidation state of $\mathrm{M} \mathrm{O}^{\mathrm{VI}}\left(\mathrm{M} \mathrm{oO}_{3}\right)$. A t $673 \mathrm{~K}$ the edge was shifted to a lower value corresponding to the lower $\mathrm{M} \mathrm{o}^{\mathrm{IV}}$ oxidation state $\left(\mathrm{M} \mathrm{OS}_{2}\right)$. A s Figs. $2 \mathrm{~A}$, B show for $\mathrm{M} \mathrm{o} / \mathrm{A} \mathrm{I}_{2} \mathrm{O}_{3}$ and $\mathrm{M} \mathrm{O} / \mathrm{TiO}_{2}$ the $\mathrm{M} \mathrm{O}^{\mathrm{IV}}$ state was al ready reached at a temperature of 448 and $423 \mathrm{~K}$, respectively. I n contrast, $\mathrm{CoMo} / \mathrm{TiO}_{2}$ (Fig. 2C) had to be sulfided at least $498 \mathrm{~K}$ to completely reach a $\mathrm{M} \mathrm{o}^{\mathrm{IV}}$ oxidation state. A t intermediate temperatures the edge position for all samples was situated between that of $\mathrm{MO}^{\mathrm{VI}}$ and $\mathrm{MO}^{\mathrm{IV}}$ pointing to a mixture of $\mathrm{MO}^{\mathrm{VI}}$ and $\mathrm{MO}^{\mathrm{IV}}$ or possibly to the presence of $\mathrm{M} \mathrm{O}^{\mathrm{V}}$.

\section{EXAFS of (Co) Mo/A $\mathrm{I}_{2} \mathrm{O}_{3}$}

E ventually, after data analysis the main EXAFS results could be summarised by considering only four temperatures corresponding to or near the temperature limits of each sulfidation stage in the TPS pattern, namely 298,423 , 523 , and $673 \mathrm{~K}$. Figure 3 displays the experimental EX A FS data of $\mathrm{Mo} / \mathrm{A} \mathrm{I}_{2} \mathrm{O}_{3}$ sulfided at these four temperatures. A s with the nearedge spectra the $\mathrm{EXAFS}$ data of $\mathrm{CoM} 0 / \mathrm{Al}_{2} \mathrm{O}_{3}$ were identical to those of unpromoted $\mathrm{M} \mathrm{O} / \mathrm{A} \mathrm{I}_{2} \mathrm{O}_{3}$. A s shown in Figs. $3 A-D$ the data quality of the raw EXA FS data was

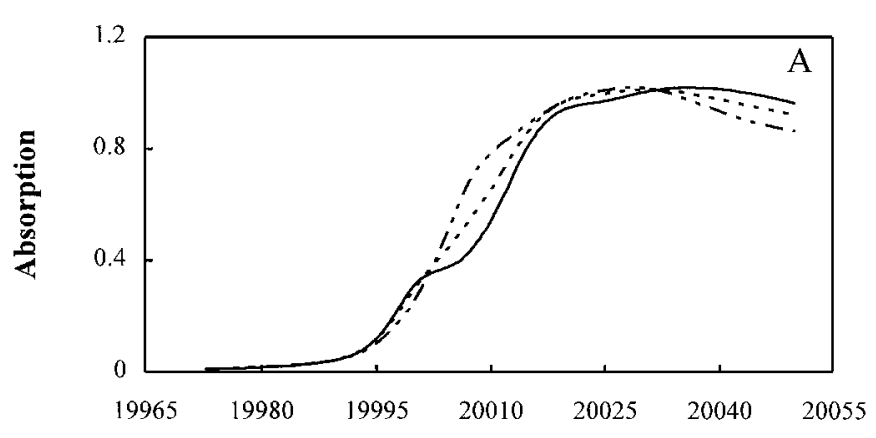

Energy (eV)
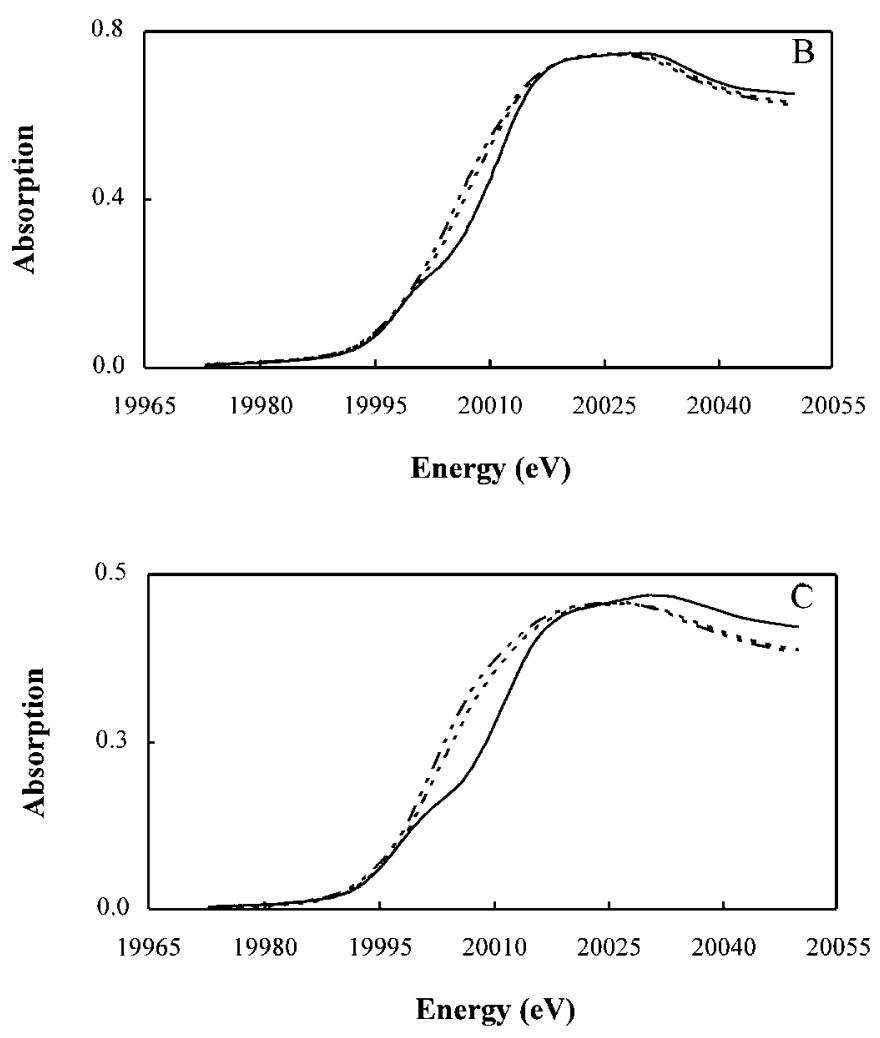

FIG. 2. XA NES spectra of (A) $\mathrm{M} \mathrm{o} / \mathrm{A} \mathrm{I}_{2} \mathrm{O}_{3}$ sulfided at $298 \mathrm{~K}(---)$, $398 \mathrm{~K}(---), 448 \mathrm{~K}(--)$; (B) $\mathrm{M} \mathrm{o} / \mathrm{TiO}_{2}$ sulfided at $298(---), 398 \mathrm{~K}$ $(---), 423 \mathrm{~K}(--)$; and (C) $\mathrm{COM} \mathrm{O}_{\mathrm{TiO}}$ sulfided at $298(---), 398 \mathrm{~K}$ $(---), 498 \mathrm{~K}(---)$.

good. The noise level was low, as expressed by a standard deviation below 0.0005 (three scans average). B ased on the noise level the Fourier transform range for data analysis was chosen from 3.6 to $14.0 \mathrm{~A}^{\circ}$. . Figure 4 shows the Fourier transforms of $\mathrm{M} \mathrm{o} / \mathrm{A} \mathrm{I}_{2} \mathrm{O}_{3}$ sulfided at various temperatures together with their best fits. The fits closely matched the experimental data in the fit region between 1.0 and $3.5 \AA$. B elow $1.0 \mathrm{~A}$ the fit deviated from the measured data due to a background feature, that was difficult to subtract from the raw data. 

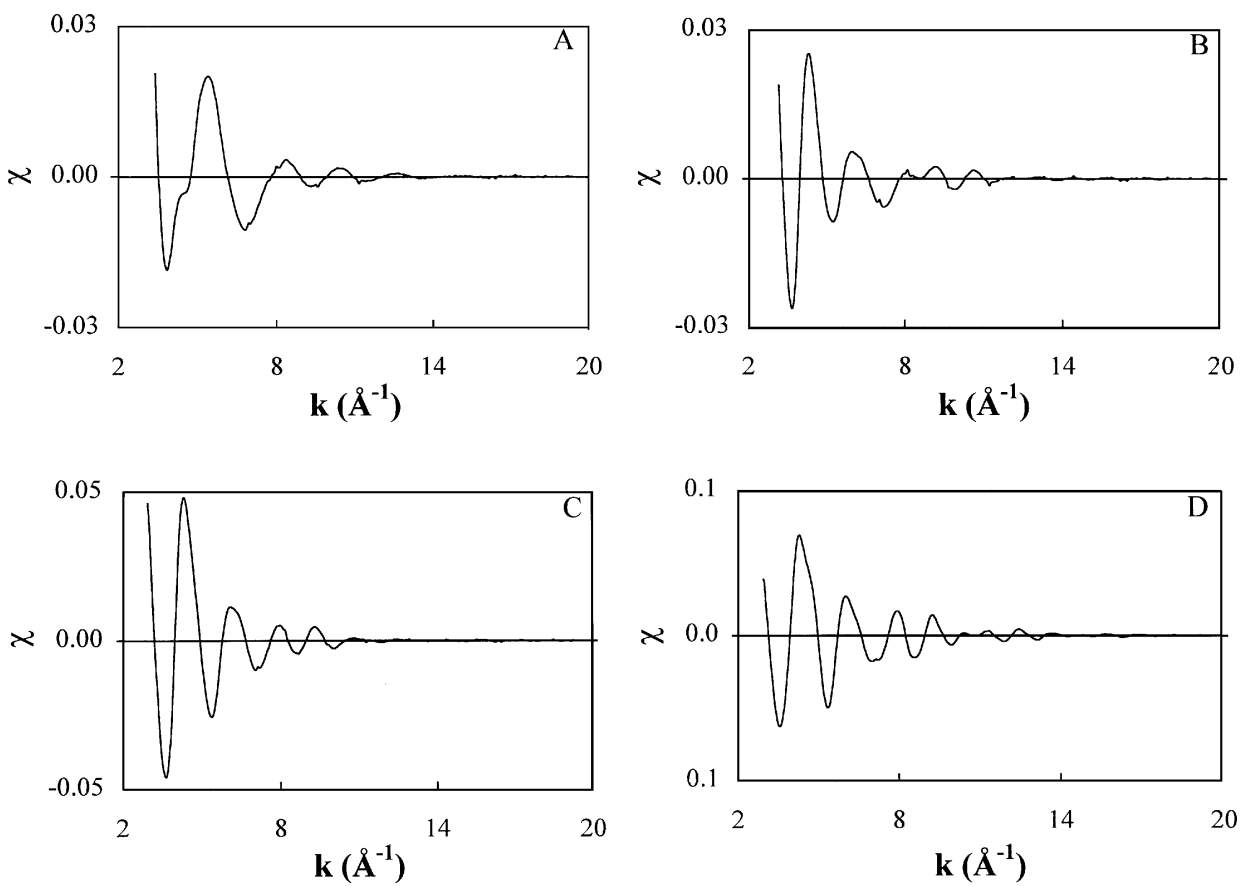

FIG. 3. EXA FS spectra (unweighted) of $\mathrm{M} \mathrm{o} / \mathrm{Al}_{2} \mathrm{O}_{3}$ sulfided at (A) $298 \mathrm{~K}$, (B) $423 \mathrm{~K}$, (C) $523 \mathrm{~K}$, (D) $673 \mathrm{~K}$.

Stage I. The Fourier transform of $\mathrm{Mo} / \mathrm{Al}_{2} \mathrm{O}_{3}$ sulfided at room temperature (Fig. 4A) mainly contained one broad peak at low $\mathrm{R}$-values characteristic of $\mathrm{M} \mathrm{O-O}$ contributions (32). Comparison of the Fourier transform of the fresh oxidic catalyst and the catalyst exposed to $\mathrm{H}_{2} \mathrm{~S}$ showed no significant changes (Fig. 4A). In accordance with this, incorporation of a M o-S contribution was not necessary to obtain a reasonable fit, confirming that at $298 \mathrm{~K}$ no $\mathrm{O}-\mathrm{S}$ exchange had taken place. The first shell of the Fourier transform was fit by two Mo-O contributions with bond distances of 1.76 and $1.92 \AA^{\circ}$ (see Table 1). A dditionally, data analysis revealed the presence of $\mathrm{M} \mathrm{O-A} \mathrm{I} \mathrm{and} \mathrm{M} \mathrm{o-M} 0$ contributions at 2.76 and $3.28 \AA^{\circ}$, respectively. A detailed description of the structure of the oxidic catalysts was already given elsewhere (32).

Stagell. U pon treatment at $363 \mathrm{~K}$ ( $\mathrm{Fig} .4 \mathrm{~B}$ ) the $\mathrm{M} \mathrm{o} / \mathrm{A} \mathrm{I}_{2} \mathrm{O}_{3}$ samples started to sulfide, as was indicated by a strong reduction of the amplitude of the Fourier transform around $1.3 \mathrm{~A}^{\circ}$ and a relative increase of the amplitude of the $(\mathrm{M} \mathrm{O}-\mathrm{S})$ peak at around $2.0 \mathrm{~A}^{\circ}$. A t $423 \mathrm{~K}$ (Fig. $4 \mathrm{C}$ ) the amplitude around $1.3 \mathrm{~A}^{\circ}$ reached a minimum value. This drastic decrease of the amplitude could be ascribed to destructive interference between M o-S and M o-O contributions (due to their phase difference of approximately $\pi$ radians (43)) and to the very high D ebye-Waller factor of the M o-S contribution. $\mathrm{D}$ ata analysis of the spectra obtained after sulfidation at $423 \mathrm{~K}$ showed a $\mathrm{M} \mathrm{O-S}$ coordination number of 4.3, together with a M o-O coordination of 0.4 at $1.98 \AA$ and $a$ M o-M o coordination of 0.2 (see Table 1). The short M o-O contribution at $1.76 \AA^{\circ}$ disappeared, while the M o-M o bond length changed from $3.28 \AA$ for the oxidic catalyst to $2.75 \AA^{\circ}$ for the sulfided sample.

Stage III. Sulfidation at temperatures higher than $423 \mathrm{~K}$ led to a further increase of amplitude of the M o-S peak at around $2.0 \AA^{\circ}$ (Figs. 4D-F). This was mainly due to a

TABLE 1

Fit Parameters Mo/A lumina Supported C atalyst

\begin{tabular}{|c|c|c|c|c|c|c|}
\hline Scatterer & $\mathrm{N}$ & $\Delta \sigma^{2}\left(10^{-4} A^{\circ}\right)$ & $R\left(A^{\circ}\right)$ & $\Delta \mathrm{E}_{0}(\mathrm{eV})$ & Var. im. ${ }^{a}$ & Var. ab. ${ }^{b}$ \\
\hline \multicolumn{5}{|c|}{ Stage I. Sulfided $298 \mathrm{~K}$} & 3.09 & 0.67 \\
\hline 0 & 3.4 & 34.0 & 1.76 & -8.0 & & \\
\hline 0 & 2.8 & 40.0 & 1.92 & 9.0 & & \\
\hline Al & 0.4 & 52.9 & 2.76 & -15.0 & & \\
\hline Mo & 0.4 & 60.0 & 3.28 & 8.7 & & \\
\hline \multicolumn{5}{|c|}{ Stage II. Sulfided $423 \mathrm{~K}$} & 5.14 & 1.35 \\
\hline 0 & 0.4 & -27.2 & 1.98 & 15 & & \\
\hline $\mathrm{S}$ & 4.3 & 238.6 & 2.46 & -0.3 & & \\
\hline Mo & 0.2 & -19.6 & 2.75 & 9.01 & & \\
\hline \multicolumn{5}{|c|}{ Stage III. Sulfided $523 \mathrm{~K}$} & 0.83 & 0.44 \\
\hline 0 & 0.8 & 19.9 & 2.00 & -0.8 & & \\
\hline $\mathrm{S}$ & 3.7 & 61.0 & 2.39 & 6.5 & & \\
\hline Mo & 1.0 & 93.1 & 2.78 & 0.3 & & \\
\hline Mo & 0.7 & 65.6 & 3.16 & -4.0 & & \\
\hline \multicolumn{5}{|c|}{ Stage IV. Sulfided $673 \mathrm{~K}$} & 0.44 & 0.18 \\
\hline 0 & 1.0 & 51.3 & 2.00 & -2.0 & & \\
\hline $\mathrm{S}$ & 5.0 & 18.0 & 2.40 & 3.8 & & \\
\hline Mo & 2.9 & 21.0 & 3.15 & 2.4 & & \\
\hline
\end{tabular}

${ }^{a, b}$ Variance imaginary and absolute parts Fourier transform according to Eq. [1]. 

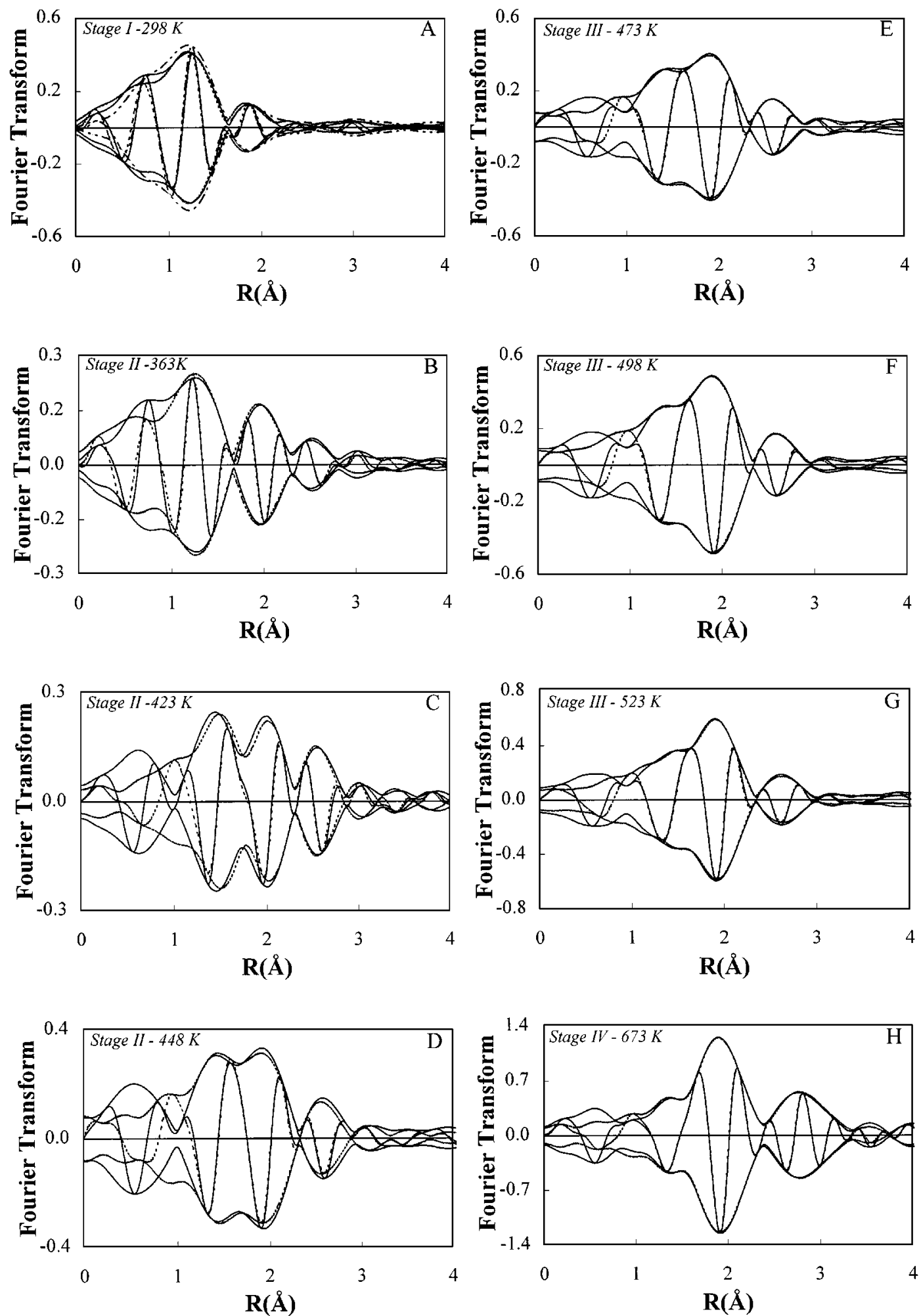

FIG . 4. Fourier transform $\left[\mathrm{K}^{2}, \Delta \mathrm{k}=4.0-12.0\right]$ of $\mathrm{M} \mathrm{o} / \mathrm{A} \mathrm{I}_{2} \mathrm{O}_{3}(---)$ and best fit (- - ) sulfided at (A) $298 \mathrm{~K}$; oxidic catalyst (-- - - - ) (B) $363 \mathrm{~K}$; (C) $423 \mathrm{~K}$; (D) $448 \mathrm{~K}$; (E) $473 \mathrm{~K}$; (F) $498 \mathrm{~K}$; (G) $523 \mathrm{~K}$; (H) $673 \mathrm{~K}$. 
lowering of the D ebye-Waller factor of the M o-S contribution, indicating that at these temperatures a less disordered structure was formed. Simultaneously, the amplitude of the peak at around $2.6 \AA^{\circ}$ increased (compare Fig. 4G with 4D) due to an increasing $\mathrm{M} \mathrm{O}-\mathrm{M}$ o contribution. $\mathrm{D}$ ata analysis of $\mathrm{M} \mathrm{o} / \mathrm{Al}_{2} \mathrm{O}_{3}$ sulfided at $523 \mathrm{~K}$ (Fig. 4G) showed besides the M o-M o contribution at $2.77 \mathrm{~A}^{\circ}$ a second M O-M o contribution with a bond distance of $3.16 \AA^{\circ}$, characteristic of $M_{0} O S_{2}$. The M o-S coordination at this temperature had dropped to a value of 3.7. The M 0-O contribution was slightly increased from a avlue of 0.4 at $423 \mathrm{~K}$ to 0.8 at $523 \mathrm{~K}$.

Stage IV. A t temperatures higher than $523 \mathrm{~K}$ the M o-M 0 contribution at $2.77 \AA^{\circ}$ decreased, while the $3.16 \AA^{\circ}$ contribution further increased. The Fourier transforms of the alumina samples sulfided at 573 and $673 \mathrm{~K}$ (Fig. 4H ) were characteristic of $\mathrm{M} \mathrm{OS}_{2}$. The M O-S coordination had increased to a value of 5.0 , while the $\mathrm{M} \mathrm{O-O}$ contribution stayed present at $2.0 \AA$ with a coordination number of 1.0 .

The values of the coordination numbers of the Mo-O, $\mathrm{M} \mathrm{o-S}$, and M o-M o contributions as a function of the sulfidation temperature are presented in Fig. 5A . It is clear that both the Mo-S and Mo-Mo contribution at $2.77 \AA$ went through a maximum value, while the Mo- 0 contribution had a minimum value. A dditionally, the $3.16 \AA^{\circ} \mathrm{Mo}-\mathrm{Mo}$ contribution steadily increased, starting at $523 \mathrm{~K}$.

\section{EXAFS of $\mathrm{Mo} / \mathrm{TiO}_{2}$}

Figure 6 displays the experimental EXAFS data and Fourier transforms of $\mathrm{Mo} / \mathrm{TiO}_{2}$ sulfided at room temperature, 423,523 , and $673 \mathrm{~K}$. The results of the data analysis are given in Table 2 and Fig. 5B. A scan be seen from Fig. 5B, the general outcome of the EXA FS analyses in terms of coordination numbers was comparable to that of $\mathrm{Mo} / \mathrm{A} \mathrm{I}_{2} \mathrm{O}_{3}$. $\mathrm{H}$ owever, also some significant differences were found.

Stage I. The Fourier transform of $\mathrm{Mo} / \mathrm{TiO}_{2}$ sulfided at room temperature (Fig. 6E) was completely different from that of the fresh oxidic catalyst. A $n$ extra node was present at $1.1 \AA$ and the maximum of the first shell was shifted to higher $\mathrm{R}$-values. This different shape of the Fourier transform was due a M O-S contribution at $2.40 \AA^{\circ}$, indicating the sulfidation of $\mathrm{Mo} / \mathrm{TiO}_{2}$ to start at room temperature.

Stage II. For $\mathrm{M} \mathrm{o} / \mathrm{TiO}_{2}$ sulfided at $423 \mathrm{~K}$ (Fig. 6F) an additional peak in the Fourier transform developed at around $3.8 \AA^{\circ}$. The analysis of this peak proved to be very difficult as will now be explained.

Figure $7 \mathrm{~A}$ presents the Fourier transform of the raw EXA FS data minus the calculated $\mathrm{M} \mathrm{O-O}$ and M o-S shell phase corrected for the Mo-Mo absorber-backscatterer pair. The optimum at $3.87 \mathrm{~A}^{\circ}$ of the imaginary part of the Fourier transform implies that this contribution can be assigned to a M o backscatterer. A Iternatively, Fig. 7B shows the same Fourier transform, but now phase corrected for the M o-Ti absorber-backscatterer pair. A ccording to the optima in the imaginary part the contribution between
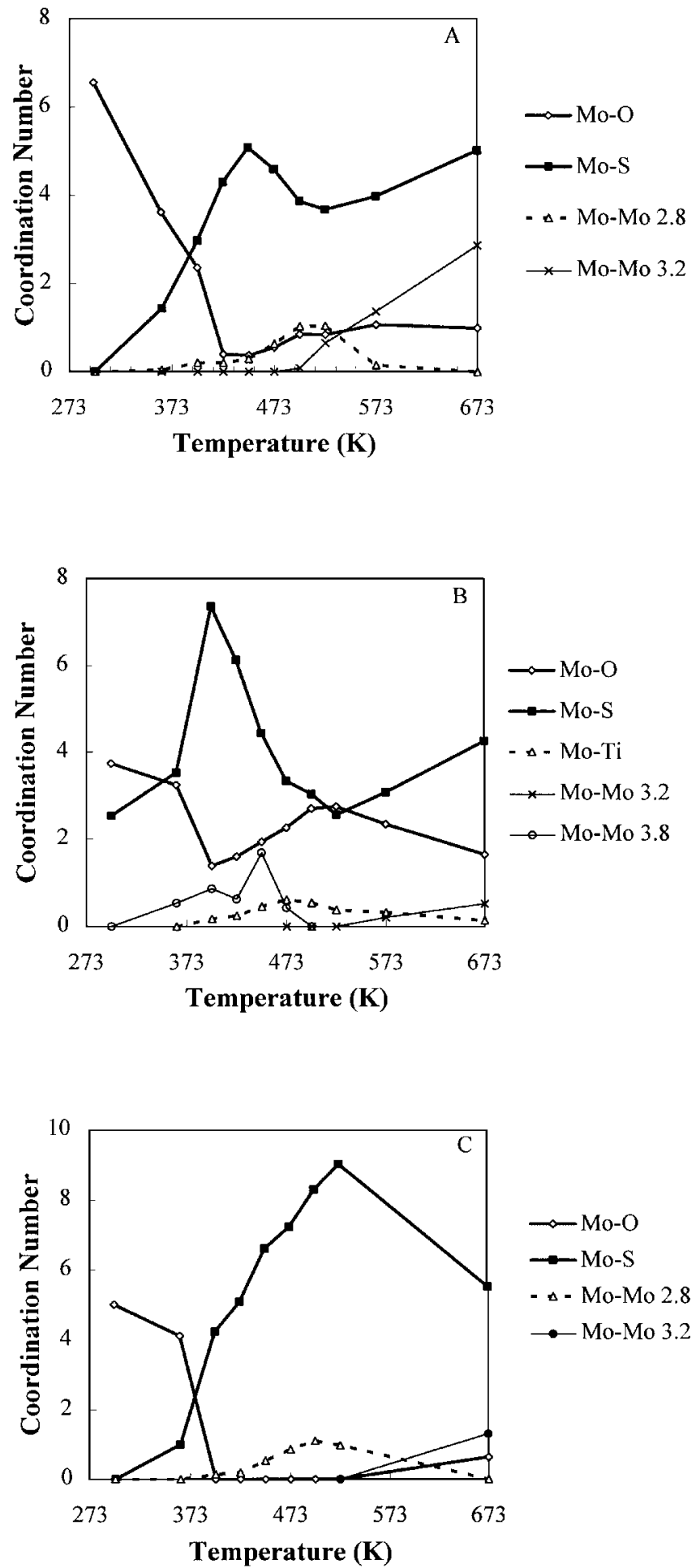

FIG. 5. Coordination numbers of the various $\mathrm{M} 0$-backscatterer contributions between 298 and $673 \mathrm{~K}$ for (A) $\mathrm{Mo}_{2} \mathrm{Al}_{2} \mathrm{O}_{3}$, (B) $\mathrm{Mo} / \mathrm{TiO}_{2}$, and (C) $\mathrm{CoM} / \mathrm{TiO}_{2}$.

3.5- $4.5 \AA^{\circ}$ can be assigned to two M o-Ti contributions at 3.8 and $4.1 \AA^{\circ}$. H owever, this did not result in a converging fit.

Similarly, the peak at around $3 A^{\circ}$ could only be fit with a M O-Ti shell at $3.01 \mathrm{~A}^{\circ}$ (see Fig. 7B). A ssigning this 

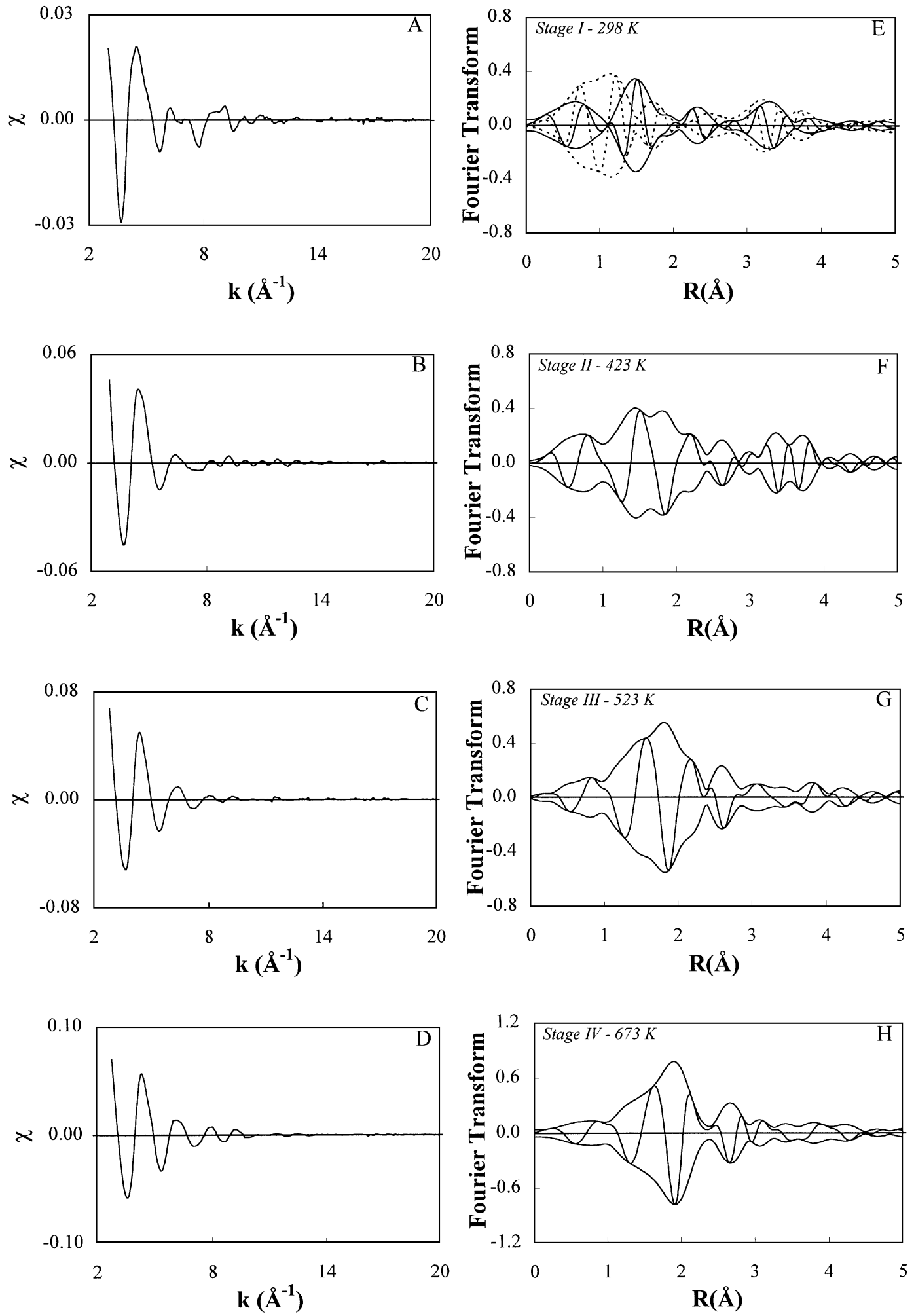

FIG. 6. EXA FS spectra (unweighted) and Fourier transforms $\left[\mathrm{k}^{2}, \Delta \mathrm{k}=3.6-14.0\right]$ of $\mathrm{M} \mathrm{o} / \mathrm{TiO}{ }_{2}$ sulfided at (A /E ) $298 \mathrm{~K} ; 0 x i d i c$ catalyst (- - -); (B/F) $423 \mathrm{~K} ;(\mathrm{C} / \mathrm{F}) 523 \mathrm{~K} ;(\mathrm{D} / \mathrm{H}) 673 \mathrm{~K}$. 
TABLE 2

Fit Parameters Mo/Titania Supported Catalyst

\begin{tabular}{|c|c|c|c|c|c|c|}
\hline Scatterer & $\mathrm{N}$ & $\Delta \sigma^{2}\left(10^{-4} A^{\circ}\right)$ & $R\left(A^{\circ}\right)$ & $\Delta \mathrm{E}_{0}(\mathrm{eV})$ & Var. im. ${ }^{a}$ & Var. ab. ${ }^{b}$ \\
\hline \multicolumn{5}{|c|}{ Stage I. Sulfided $298 \mathrm{~K}$} & 8.32 & 2.82 \\
\hline 0 & 0.8 & 79.0 & 1.64 & 15.5 & & \\
\hline 0 & 2.9 & 65.9 & 1.99 & -2.9 & & \\
\hline $\mathrm{s}$ & 2.5 & 300.0 & 2.40 & 8.3 & & \\
\hline $\mathrm{Ti}$ & 0.4 & 46.3 & 2.78 & 10.0 & & \\
\hline Mo & 2.5 & 77.4 & 3.55 & -5.3 & & \\
\hline \multicolumn{5}{|c|}{ Stage II. Sulfided $423 \mathrm{~K}$} & 2.14 & 0.90 \\
\hline 0 & 1.6 & 79.9 & 1.95 & 0.9 & & \\
\hline $\mathrm{s}$ & 6.1 & 235.8 & 2.40 & -1.1 & & \\
\hline $\mathrm{Ti}$ & 0.3 & -23.4 & 2.98 & 1.9 & & \\
\hline Mo & 0.6 & -28.2 & 3.87 & -1.4 & & \\
\hline \multicolumn{5}{|c|}{ Stage III. Sulfided $523 \mathrm{~K}$} & 2.15 & 1.22 \\
\hline 0 & 2.8 & 100.2 & 2.02 & -0.7 & & \\
\hline $\mathrm{s}$ & 2.6 & 74.6 & 2.37 & 5.5 & & \\
\hline $\mathrm{Ti}$ & 0.4 & -23.5 & 3.06 & -12.1 & & \\
\hline \multicolumn{5}{|c|}{ Stage IV. Sulfided $673 \mathrm{~K}$} & 0.45 & 0.23 \\
\hline 0 & 1.7 & 96.9 & 2.00 & 2.5 & & \\
\hline $\mathrm{S}$ & 4.3 & 63.5 & 2.39 & 5.9 & & \\
\hline Mo & 0.2 & 32.6 & 2.81 & 3.0 & & \\
\hline Mo & 1.0 & 32.6 & 3.15 & 3.0 & & \\
\hline \multicolumn{5}{|c|}{ A Iternative fit second shell } & 0.34 & 0.22 \\
\hline $\mathrm{Ti}$ & 0.1 & -53.4 & 2.97 & -1.4 & & \\
\hline Mo & 0.5 & -14.3 & 3.15 & 6.5 & & \\
\hline
\end{tabular}

$\mathrm{a}, \mathrm{b}$ Variance imaginary and absolute parts Fourier transform according to Eq. [1].

contribution to a Mo backscatterer had to include two M o-M o contributions at 2.8 and $3.2 \mathrm{~A}^{\circ}$, which did not lead to a converging fit. The signal between 2.0 and $2.5 A^{\circ}$ is due to an incomplete subtraction of the M O-S contribution and was resolved after a full optimisation of all shells.

$\mathrm{H}$ owever, the high negative values for the D ebye-Waller factors of the M o-M o and M o-Ti contributions make the analysis results highly questionable. Moreover, regarding the results obtained with $\mathrm{Mo} / \mathrm{A} \mathrm{I}_{2} \mathrm{O}_{3}$ the assignment of the lower peak to a Mo-Mo contribution at around $2.8 \mathrm{~A}^{\circ}$ and the higher peak to a Mo-Ti contribution at around $3.9 \AA^{\circ}$ seems more likely. Probably, the use of a theoretical $\mathrm{M} \mathrm{O}-\mathrm{Ti}$ reference, which assumes a $\mathrm{M} \mathrm{O}^{0}-\mathrm{Ti}^{0}$ pair instead of a M O $\mathrm{VI}^{-} \mathrm{Ti}^{\mathrm{IV}}$ pair led to current outcome of the analysis. In view of the above considerations the analysis results of the second shell should be looked upon with care as indicated in Table 2.

Stage III. For $\mathrm{Mo} / \mathrm{TiO}_{2}$ no $\mathrm{Mo}-\mathrm{Mo}$ contribution was present anymore at $523 \mathrm{~K}$ (Fig. 6G ). O nly the M o-Ti contribution at $3.06 \mathrm{~A}^{\circ}$ was found next to the usual M 0-O and Mo-S contributions.

Stage IV. The Fourier transform of the sample sulfided at $673 \mathrm{~K}$ (Fig. $6 \mathrm{H}$ ) was characteristic of $\mathrm{M} \mathrm{OS}_{2}$. The second shell could be fit with a combination of M o-M o at $3.16 \mathrm{~A}^{\circ}$ and $\mathrm{M} \mathrm{O}-\mathrm{Ti}$ at $2.97 \mathrm{~A}^{\circ}$. H owever, in this case the second shell could equally be fit with two M o-M o contributions at 2.81 and $3.15 \AA^{\circ}$ (see Table 2). The latter analysisis more realistic, since in the alternative analysis the $D$ ebye-Waller factors of the M O-Ti and M o-M o contributions are again negative questioning their credibility.

\section{EXAFS of $\mathrm{COM} \mathrm{o/TiO} 2$}

Figure 8 displays the raw E X A FS data and Fourier transforms of $\mathrm{CoM}$ o/ $/ \mathrm{TiO}_{2}$ sulfided at different temperatures. The results of the data analysis are given in Table 3 and Fig. $5 \mathrm{C}$.

Stage I. $\mathrm{CoMo} / \mathrm{TiO}_{2}$ sulfided at room temperature (Fig. 8E ) showed a Fourier transform that was similar to that of the fresh oxidic catalyst, although the amplitude of
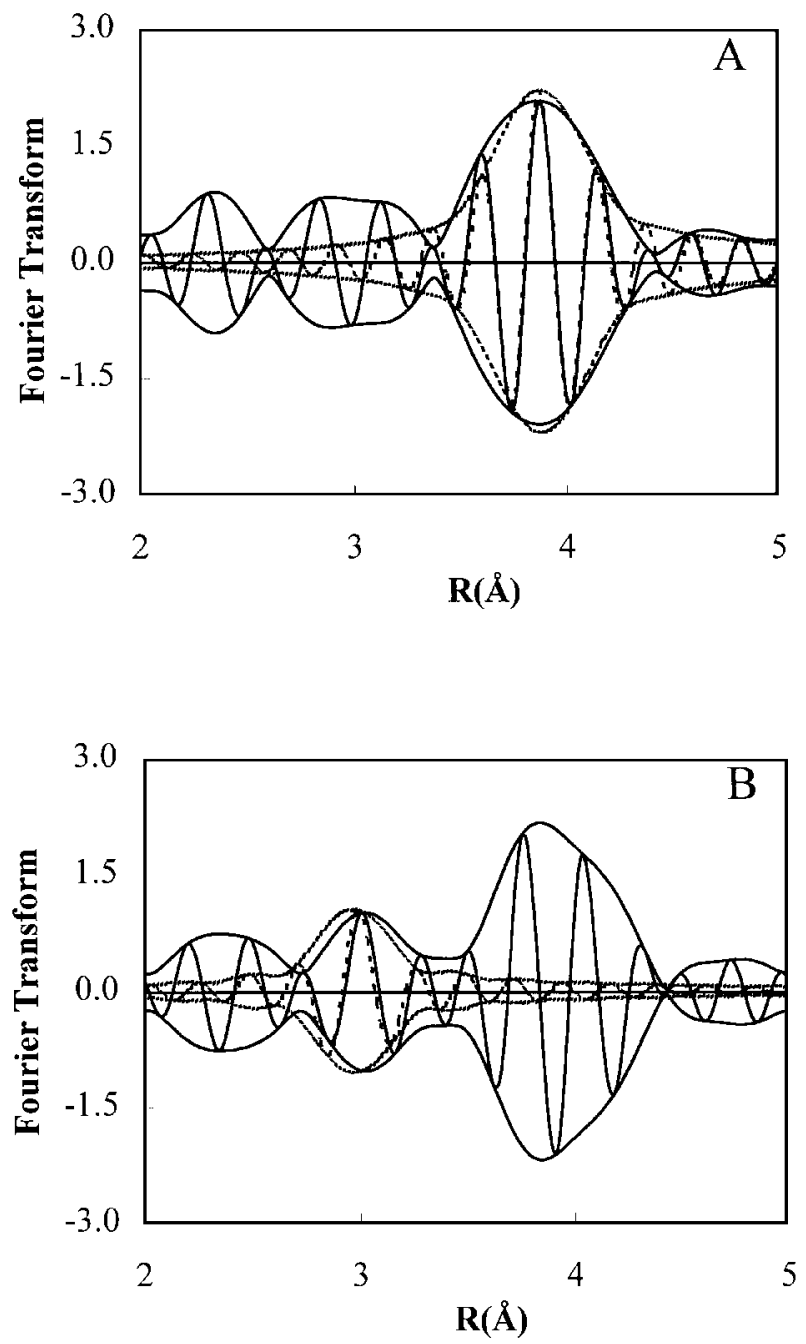

FIG. 7. Difference files for $\mathrm{Mo}_{0} / \mathrm{TiO}_{2}$ sulfided at $423 \mathrm{~K}$ (A) $\mathrm{M} \mathrm{O}_{0}-\mathrm{Mo}_{0}$ contribution: Fourier transform $\left(\mathrm{k}^{3}, \Delta \mathrm{k}=3.6-14.0\right.$, M o-M o phase corrected) of EXA FS spectrum minus calculated $\mathrm{M} \mathrm{O}^{-} \mathrm{S}$ and $\mathrm{M} \mathrm{O}-\mathrm{O}$ contributions (- - ) and fit with M O-Mo contribution (-- -) (B) M o-Ti contribution: Fourier transform $\left(\mathrm{k}^{3}, \Delta \mathrm{k}=3.6-14.0, \mathrm{M} \mathrm{o-Ti}\right.$ phase corrected) of EXAFS spectrum minus calculated M $0-S$ and M $0-0$ contributions (- - $)$ and fit with M O-Ti contribution (-- -). 

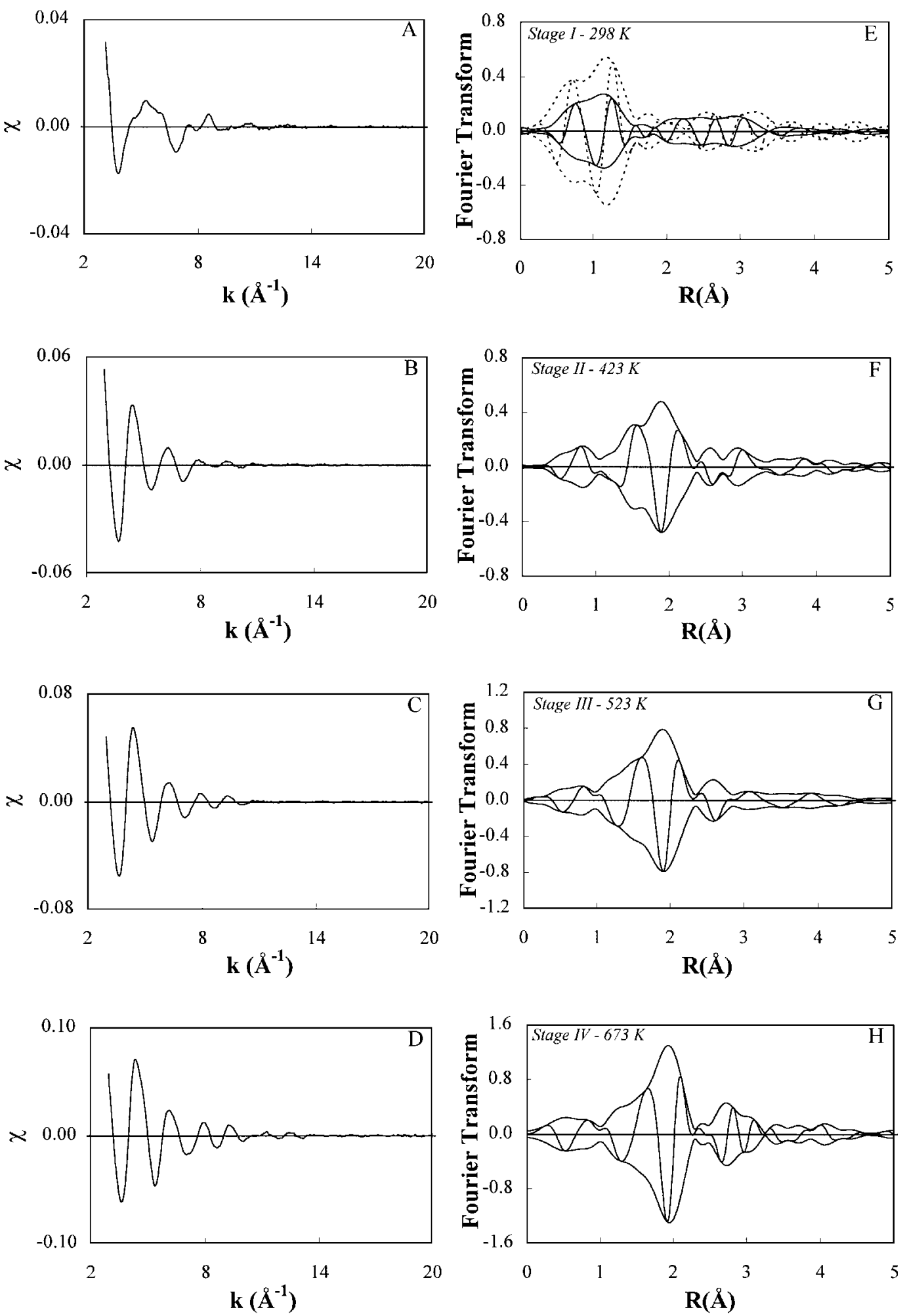

FIG. 8. EXA FS spectra (unweighted) and Fourier transforms $\left(\mathrm{K}^{2}, \Delta \mathrm{K}=3.6-14.0\right)$ of $\mathrm{CoM}$ o/TiO ${ }_{2}$ sulfided at (A /E ) $298 \mathrm{~K}$; oxidic catalyst (- - -); (B/F) $423 \mathrm{~K} ;(\mathrm{C} / \mathrm{F}) 523 \mathrm{~K} ;(\mathrm{D} / \mathrm{H}) 673 \mathrm{~K}$. 
TABLE 3

Fit Parameters C o- M o/Titania Supported Catalyst

\begin{tabular}{|c|c|c|c|c|c|c|}
\hline Scatterer & $\mathrm{N}$ & $\Delta \sigma^{2}\left(10^{-4} \AA^{0}\right)$ & $R\left(A^{\circ}\right)$ & $\Delta \mathrm{E}_{0}(\mathrm{eV})$ & Var. im. ${ }^{a}$ & Var. ab. ${ }^{b}$ \\
\hline \multicolumn{5}{|c|}{ Stage I. Sulfided $298 \mathrm{~K}$} & 4.33 & 1.49 \\
\hline 0 & 2.5 & 50.2 & 1.75 & -4.1 & & \\
\hline 0 & 2.5 & 70.1 & 1.94 & 8.6 & & \\
\hline $\mathrm{Ti}$ & 1.1 & 123.9 & 2.73 & 10.7 & & \\
\hline Mo & 1.8 & 100.4 & 3.06 & -9.3 & & \\
\hline \multicolumn{5}{|c|}{ Stage II. Sulfided $423 \mathrm{~K}$} & 1.34 & 0.48 \\
\hline $\mathrm{s}$ & 5.1 & 157.4 & 2.40 & -1.1 & & \\
\hline Mo & 0.2 & -1.5 & 2.75 & 3.6 & & \\
\hline $\mathrm{Ti}$ & 1.2 & 62.9 & 3.50 & 8.6 & & \\
\hline \multicolumn{5}{|c|}{ Stage III. Sulfided $523 \mathrm{~K}$} & 0.42 & 0.20 \\
\hline $\mathrm{S}$ & 9.0 & 159.4 & 2.40 & 1.3 & & \\
\hline Mo & 1.0 & 41.6 & 2.73 & 11.8 & & \\
\hline \multicolumn{5}{|c|}{ Stage IV. Sulfided $673 \mathrm{~K}$} & 1.02 & 0.49 \\
\hline 0 & 0.7 & 7.7 & 1.98 & 0.5 & & \\
\hline $\mathrm{S}$ & 5.5 & 34.9 & 2.40 & 2.8 & & \\
\hline Mo & 1.3 & 6.2 & 3.17 & -1.2 & & \\
\hline
\end{tabular}

$\mathrm{a}, \mathrm{b}$ Variance imaginary and absolute parts Fourier transform according to Eq. [1].

the first shell was much lower. However, no Mo-S contribution could be incorporated, indicating that sulfidation had not taken place at room temperature. The change in the M o-O coordination upon sulfidation compared to the fresh oxidic catalyst is therefore hard to explain. The only difference is that the oxidic catalyst was dried at $393 \mathrm{~K}$ in $\mathrm{H}$ e flow before characterisation (32), whereas the sulfided one in this study was not. The removal of physisorbed water apparently influences the structure of the molybdenum oxide entities on the titania surface.

Stages II-IV. A s displayed in Fig. $5 \mathrm{C}$ and Figs. 8F-H the trends in the coordination numbers of the various $\mathrm{EXAFS}$ contributions for $\mathrm{CoM}$ o/TiO 2 were different than observed with the other samples. The maximum in the $\mathrm{Mo-S}$ coordination number was shifted from $398 \mathrm{~K}$ for $\mathrm{Mo} / \mathrm{TiO}_{2}$ to $523 \mathrm{~K}$ for the promoted catalyst. A Iso, the M 0-O contribution completely disappeared al ready at $398 \mathrm{~K}$. Similar to $\mathrm{M} \mathrm{o} / \mathrm{A} \mathrm{I}_{2} \mathrm{O}_{3}$ a $\mathrm{M} \mathrm{o-M} \mathrm{o} \mathrm{contribution} \mathrm{was} \mathrm{observed} \mathrm{at} \mathrm{around}$ $2.8 \mathrm{~A}$ that reached a maximum value at $548 \mathrm{~K}$. A t $673 \mathrm{~K}$ only a M O-M o contribution at $3.16 \mathrm{~A}^{\circ}$ was present.

\section{DISCUSSION}

The most important results can be summarised as follows:

(1) The structural parameters of the involved intermediate Mo species have been obtained as a function of the sulfidation temperature (see Fig. 5).

(2) A II intermediate species during sulfidation contain M o-O bonds with a bond length of $2.0 \mathrm{~A}$ that can be ascribed to M 0-O linkages with the support as was already observed in catalysts sulfided at $673 \mathrm{~K}$ (32).
(3) For $\mathrm{Mo}_{\mathrm{Al}} \mathrm{O}_{3}, \mathrm{CoMo} / \mathrm{Al}_{2} \mathrm{O}_{3}$, and $\mathrm{CoM} \mathrm{o} / \mathrm{TiO} 2$ intermediate species are observed during sulfidation with a Mo-M o bond length of $2.8 \AA^{\circ}$.

(4) For $\mathrm{Mo}_{\mathrm{A} \mathrm{I}} \mathrm{O}_{3}, \mathrm{CoMo} / \mathrm{Al}_{2} \mathrm{O}_{3}$, and $\mathrm{Mo} / \mathrm{TiO} 2$ all $\mathrm{Mo}$ atoms are in a + IV valency state at sulfidation temperatures of 448 and $423 \mathrm{~K}$, respectively. In $\mathrm{CoM}$ o/TiO 2 all M o atoms are in a +IV valency state after sulfidation at temperature higher than $498 \mathrm{~K}$.

(5) For $\mathrm{Mo}_{2} \mathrm{Al}_{2} \mathrm{O}_{3}, \mathrm{CoM} \mathrm{o} / \mathrm{Al}_{2} \mathrm{O}_{3}$, and $\mathrm{CoM} \mathrm{o} / \mathrm{TiO}$ sulfidation only starts at temperatures above room temperature. Sulfidation of $\mathrm{Mo}_{\mathrm{O}} \mathrm{TiO}_{2}$ already takes place at room temperature.

In the following discussion these results will be combined with available literature data to develop a model for the sulfidation of molybdenum oxide catalysts.

\section{(Co) $\mathrm{Mo}_{\mathrm{A}} \mathrm{Al}_{2} \mathrm{O}_{3}$}

Stagel ( $298 \mathrm{~K}$ ). The EX A FS data obtained at room temperature show that the catalyst was still completely oxidic. To enable 0 - $S$ exchange the temperature had to be raised above room temperature in agreement with the observed consumption of $\mathrm{H}_{2} \mathrm{~S}$ in the TPS pattern. The structure of the molybdenum oxide species can be visualised as depicted in Fig. 9 (structures $A$ and $A^{\prime}$ ). The low value of 0.4 for the M o-M o coordination number suggests that the main part of the $\mathrm{Mo}$ is present as a mononuclear species. These findings agree with the presence of predominantly $\mathrm{M} \mathrm{OO}_{4}^{2-}$ species in the basic impregnation solution (44), which leads to a monomolybdate surface species (45).

Stage II (298-448 K). The first sulfidation stage of the (Co) $\mathrm{Mo}_{0} / \mathrm{Al}_{2} \mathrm{O}_{3}$ catalysts has been described by several

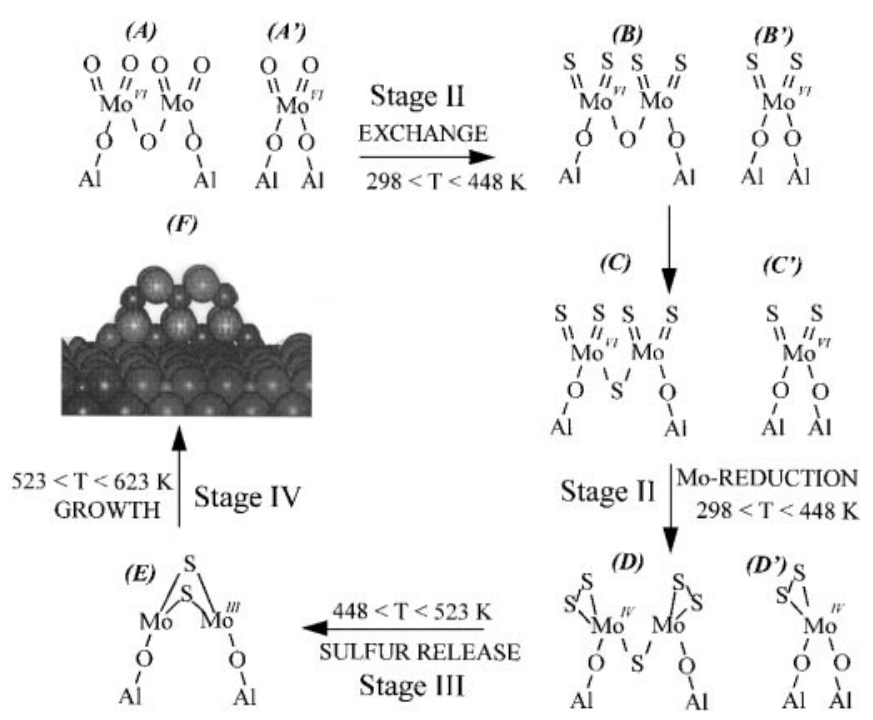

FIG. 9. R epresentation of the several stages of the sulfidation mechanism for $\mathrm{MO}_{\mathrm{A}} \mathrm{I}_{2} \mathrm{O}_{3}$. 
authors (21-31) as an 0-S exchange on molybdenum:

$$
\mathrm{Mo}^{\mathrm{VI}} \mathrm{O}_{y}+x \mathrm{H}_{2} \mathrm{~S} \rightarrow \mathrm{MoV}^{\mathrm{VI}} \mathrm{O}_{y-x} \mathrm{~S}_{x}+x \mathrm{H}_{2} \mathrm{O} \text {. }
$$

Weber et al. (46) proposed on the basis of X PS and infrared emission spectroscopy experiments that terminal $\mathrm{Mo}=0$ groups are more reactive towards sulfur exchange than bridging M O-O - M o groups.

O ur EX A FS data indeed show an exchange of oxygen for sulfur. U pon sulfidation above room temperature the M o-S coordination increases, while simultaneously the M o-O coordination drops. The exchange can be depicted as shown in Fig. 9 (structures $B$ and $B^{\prime}$ ). Since initially the M o-M $O$ distance of $3.28 A^{\circ}$ present in the oxidic catalyst increases to $3.36 \mathrm{~A}^{\circ}$ at $363 \mathrm{~K}$ it is proposed that the exchange of terminal $\mathrm{Mo}=0$ groups for sulfur is followed by sulfidation of (part of) the bridging $\mathrm{M} \mathrm{O-O-M} \mathrm{o} \mathrm{linkages.} \mathrm{A} \mathrm{s} \mathrm{a} \mathrm{result}$ dimers are formed with possible structure as structure $C$ in Fig. 9. M onomers might react to a species like structure $C^{\prime}$.

Weber et al. (46) reported that after exchange of oxygen atoms for sulfur two terminal $\mathrm{Mo}=\mathrm{S}$ groups on neighbouring $\mathrm{M} \mathrm{O}$ atoms can react under formation of a bridged $\mathrm{S}_{2}^{2-}$ ligand and simultaneous reduction of $\mathrm{Mo}^{\mathrm{VI}}$ to $\mathrm{MoV}^{\mathrm{V}}$. In addition Muijsers et al. (31) proposed that two terminal $M O=S$ groups on the same $M O$ atom can be converted to a $\mathrm{M} \mathrm{O}^{\mathrm{IV}}=\mathrm{S}_{2}$ group. Both reactions can be represented according to:

$$
\begin{aligned}
\mathrm{Mo}^{\mathrm{VI}}+x \mathrm{e}^{-} & \rightarrow \mathrm{Mo}^{(\mathrm{VI}-x)} \\
2 \mathrm{~S}^{2-} & \rightarrow \mathrm{S}_{2}^{2-}+2 \mathrm{e}^{-} .
\end{aligned}
$$

In our experiments the changing position of the M o-K edge indicates that the $0-S$ exchange is followed by a reduction to $\mathrm{M} \mathrm{O}^{\mathrm{V}} / \mathrm{M} \mathrm{O}^{\mathrm{IV}}$. A t $448 \mathrm{~K}$ all $\mathrm{Mo}$ atoms are in the + IV valency state. This would suggest that a reduction to $\mathrm{M} \mathrm{O}^{\mathrm{V}}$ under formation of bridged $\mathrm{S}_{2}^{2-}$ ligands is rare, although the Mo-Mo distance of $2.75 \mathrm{~A}$ can be associated with molybdenum sulfide clusters with bridging $\mathrm{S}_{2}^{2-}$ ligands (47). H owever, on basis of the observed edge position it is proposed that mainly terminal $\mathrm{S}_{2}^{2-}$ ligands are formed with simultaneous reduction of the $\mathrm{MO}^{\mathrm{VI}}$ ions to $\mathrm{M} \mathrm{O}^{\mathrm{IV}}$. A s depicted in Fig. 9 structure $D$ and $D^{\prime}$ then represent the type of species than are formed after sulfidation at $423 / 448 \mathrm{~K}$. The M o-M o distance in the dimer is found to be $2.75 \AA$.

The depicted structures in Fig. 9 are not in full agreement with the structural parameters in Table 1 . The M o-S coordination is expected to be 3 instead of 4 and the $M$ o- $O$ coordination should be 1 . This discrepancy is described to the complexity of the M o species that makes it difficult to obtain a good fit of the experimental EXAFS data in this temperature region. Next to destructive interference between the M O-O and M o-S contribution the structural disorder is very high as indicated by the high Debye-Waller factors. This does not make it impossible to obtain reason- able coordination parameters but the accuracy will be less than for more ordered structures. A ccordingly, due to the overlap of the $\mathrm{M} \mathrm{O-O}$ and $\mathrm{M} \mathrm{O-S}$ shells the high disorder in the M O-S contribution forces the calculated M 0-O coordination number to be lower. For this reason we believe that the M 0-O coordination gradually decreases from 373 to $498 \mathrm{~K}$ as would be expected instead of going through a minimum value as shown in Fig. $5 \mathrm{~A}$.

In an earlier study on $\mathrm{M} \mathrm{o} / \mathrm{SiO}_{2}$ catalysts the presence of $\mathrm{a} \mathrm{M} \mathrm{OS}_{3}$ as an intermediate during sulfidation was assumed to be present (28). A Ithough the structure of $\mathrm{MoS}_{3}$ is still a matter of debate and is described both as a linear chain $(48,49)$ and as an aggregation of triangular $\mathrm{M} \mathrm{O}_{3}$-sulfur clusters (50) both models invoke a M o-M o distance of about $2.77 \AA$ and the presence of bridging disulfide ligands. The low value of 0.2 for the M o-M o coordination number suggests that at $423 \mathrm{~K}$ the majority of the $\mathrm{Mo}$ atoms is present as a mononuclear species (e.g., species $D^{\prime}$ in Fig. 9), which makes the presence of $\mathrm{M} \mathrm{OS}_{3}$ or a MoS 3 like species as intermediate highly unlikely.

Stage III (448-523 K). The next stage in the sulfidation mechanism has to account for both the observed $\mathrm{H}_{2} \mathrm{~S}$ release in the TPS and the decrease of the M o-S coordination number as determined with EXAFS.

$M$ uijsers et al. (31) reported that in complexes containing both terminal and bridging $\mathrm{S}_{2}^{2-}$ ligands the terminal $\mathrm{S}_{2}^{2-}$ groups can undergo reductive elimination to elemental sulfur, while simultaneously the bridging $\mathrm{S}_{2}^{2-}$ groups are reduced to $S^{2-}$ ligands. Weber et al. (51) suggested that in the sulfidation of $\mathrm{M} \mathrm{OO}_{3}$ a bridging $\mathrm{S}_{2}^{2-}$ group can be reduced by hydrogen to a terminal $\mathrm{S}^{2-}$ ligand and $\mathrm{H}_{2} \mathrm{~S}$. H owever, since under the conditions of high temperature and the presence of $\mathrm{H}_{2}$ terminal $\mathrm{S}^{2-}$ ligands are not stable, their formation here is not very likely.

We propose that in this stage a kind of reductive elimination of the terminal $S_{2}^{2-}$ groups takes place followed by reaction with $\mathrm{H}_{2}$ leading to formation of reduced $\mathrm{M} O$ centers and $\mathrm{H}_{2} \mathrm{~S}$. (Transformation of $\mathrm{D}\left(\mathrm{D}^{\prime}\right)$ into $\mathrm{E}$ in Fig. 9). A Ithough only the genesis of bridging $S^{2-}$ ligands is depicted the formation of bridged $\mathrm{S}_{2}^{2-}$ groups (and $\mathrm{M} \mathrm{o}^{\prime \prime}$ centers) might also take place. The occurrence of these types of reactions has been described by Diemann et al. (51). The creation of $\mathrm{M} \mathrm{O}$ " sites through reductive elimination of sulfur from corner and edge sites in $\mathrm{M} \mathrm{OS}_{2}$ was reported by $M$ üller et al. (52) in their study on the adsorption of carbon monoxide on reduced $\mathrm{M} \mathrm{OS}_{2} /$ alumina catalysts. The value of 1.0 for the Mo-M o contribution at $2.78 \AA^{\circ}$ suggests that the mononuclear $M 0$ species have formed dimers or even larger aggregates. The appearance of a M o-M o contribution at $3.16 \AA$, characteristic of $\mathrm{M} \mathrm{OS}_{2}$, indicates that also larger particles are formed. The remaining presence of the M o-O contribution indicates that the Mo species are still stablised by the support, which prevents the sintering of the coordinatively unsaturated M o species. 
It is likely that on cooling to room temperature under $\mathrm{H}_{2} \mathrm{~S} / \mathrm{H}_{2}$ chemisorption of $\mathrm{H}_{2} \mathrm{~S}$ takes place on the coordinatively unsaturated $\mathrm{Mo}$ atoms explaining the higher M o-S coordination number found with EXAFS. Since the position of the preedge still corresponds to a M O $\mathrm{O}^{\mathrm{IV}}$ oxidation state also oxidation of the reduced $\mathrm{M}$ o centers has to take place during cooling down, likely accompanied by formation of $S_{2}^{2-}$ ligands.

Stage IV (523-673 K). A fter the release of sulfur the TPS pattern displays a further uptake of $\mathrm{H}_{2} \mathrm{~S}$. A the same time, according to the EX A FS analysis, the M O-M o contribution at $2.77 \mathrm{~A}^{\circ}$ quickly decreases, while the M o-M o contribution at $3.16 \mathrm{~A}^{\circ}$, characteristic of $\mathrm{M} \mathrm{OS}_{2}$, further increases. Clearly, the $\mathrm{M}$ o-dimers sinter to larger clusters with the $\mathrm{M} \mathrm{OS}_{2}$ structure (structure F) as is shown in Fig. 9. Since the $\mathrm{M} \mathrm{o-O} \mathrm{co-}$ ordination remains nearly constant at a value of about 1 the $\mathrm{Mo}$ atoms clearly stay in close contact with the support. In fact one would expect a decrease of the M 0-O contribution, since sintering occurs through sulfidation of $\mathrm{M} \mathrm{O-O}-\mathrm{A}$ I linkages. Likely, the changes of the $\mathrm{M}$ 0-O coordination number occur within the limits of accuracy, which are influenced by the high degree of structural disorder and the interference between the $\mathrm{M} \mathrm{O}-\mathrm{O}$ and $\mathrm{MO}-\mathrm{S}$ contribution as mentioned above.

$\mathrm{Mo}_{\mathrm{TiO}}$

The sulfidation of titania-supported Mo samples proceeds differently than those of alumina. Figure $5 B$ shows that the sulfidation of $\mathrm{M} \mathrm{O} / \mathrm{TiO}_{2}$ already starts at room temperature. This can be explained by the presence of larger molybdenum oxide particles on titania compared to alumina ( $\mathrm{N}_{\mathrm{M} \mathrm{O}_{\mathrm{M}} \mathrm{M}_{\mathrm{O}}}$ of 2.5 and 0.4 , respectively), which are more susceptible to sulfidation. When the temperature is raised the $\mathrm{M} \mathrm{OO}{ }_{x} \mathrm{~S}_{y}$ particles disintegrate indicated by the decrease of the M o-M o coordination number from a value of 2.5 at $298 \mathrm{~K}$ to 0.6 at $423 \mathrm{~K}$. Simultaneously, the exchange of lattice oxygen for sulfur causes the M 0-M o distance to increase from 3.55 to $3.87 \mathrm{~A}^{\circ}$. Finally, at $523 \mathrm{~K}$ no Mo backscatterer contribution is present in the Fourier transform, pointing to the formation of mononuclear or highly distorted $\mathrm{M} \mathrm{OO}_{x} \mathrm{~S}_{\mathrm{y}}$ species. The increase of the $\mathrm{M} \mathrm{O-Ti} \mathrm{contribution} \mathrm{is} \mathrm{in} \mathrm{accor-}$ dance with such a disintegration of $\mathrm{M} \mathrm{OO}_{x} \mathrm{~S}_{\mathrm{y}}$ particles. $\mathrm{B}$ ased on the EXA FS data (despite the drawbacks concerning the credibility of the $\mathrm{M} \mathrm{O-Ti} \mathrm{contribution} \mathrm{as} \mathrm{explained} \mathrm{in} \mathrm{the} \mathrm{re-}$ sults section) the structure of the $\mathrm{M} \mathrm{OO}_{x} \mathrm{~S}_{\mathrm{y}}$ clusters at $523 \mathrm{~K}$ can be described as mononuclear Mo species linked to two support oxygens and two terminal sulfur atoms.

Similar to alumina the M o-S coordination number goes through a maximum value with increasing temperature. I is assumed that between 398 and $523 \mathrm{~K}$ an identical reduction of $\mathrm{S}_{2}^{2-}$ ligands takes place. However, the absence of the expected $\mathrm{H}_{2} \mathrm{~S}$ release peak in the TPS profile, as observed for alumina, seems in contradiction with this assumption. $\mathrm{H}$ owever, this might well be ascribed to the nature of the titania support. H uisman (53) showed that surface oxygen ions of titania can be exchanged by sulfur to a considerable degree. Thus the sulfur liberated from the $\mathrm{M} \mathrm{OO}_{x} \mathrm{~S}_{y}$ clusters reacts with the support according to:

$$
\mathrm{TiO}_{2}+x \mathrm{H}_{2} \mathrm{~S} \rightarrow \mathrm{TiO}_{2-x} S_{x}+x \mathrm{H}_{2} \mathrm{O} .
$$

When the temperature is raised from 523 to $673 \mathrm{~K}$ the molybdenum sulfide monomers aggregate to $\mathrm{MOS}_{2}$, as can be seen from the M o-M o contribution at $3.16 \AA^{\circ}$. I n accordance, the M o-Ti contribution drops to a lower value. It was already pointed out that at $673 \mathrm{~K}$ this M o-Ti contribution can be equally well fit with a M O-M o contribution at $2.80 \mathrm{~A}^{\circ}$. This distance is close to the M o-M o distance of $2.77 \AA$ found for the dimer species in alumina.

\section{Influence of the A ddition of $\mathrm{CO}$}

The addition of $\mathrm{Co}$ to $\mathrm{Mo} / \mathrm{A} \mathrm{I}_{2} \mathrm{O}_{3}$ catalyst causes no observable change in the EXAFS data. However, the TPS profiles (see Fig. 1) are clearly different. The shift of the $\mathrm{H}_{2} \mathrm{~S}$ release peak to lower temperatures on addition of $\mathrm{CO}$ agree with the results of M oulijn and coworkers (54). These authors concluded that $\mathrm{Co}$ accelerates the sulfiding of $\mathrm{M} 0$, which is, however, not observed in the EXAFS data. This discrepancy is hard to explain and might have to do with the different character of a TPS and EXAFS experiment. TPS experiments are dynamic experiments in which the temperature is continuously raised, while in EXA FS experiments the system is allowed to equilibrate at definite temperatures of sulfidation. If $\mathrm{Co}$ accelerates the rate of sulfidation, but not the extent of sulfidation, this is not observed with EXAFS. Furthermore, the $\mathrm{H}_{2} \mathrm{~S} / \mathrm{H}_{2}$ ratio used in the EXA F S experiments is different from the TPS experiments. A Iternatively, one might argue that the sulfiding of cobalt oxide species is superimposed on the TPS pattern of the molybdenum oxide species, causing a shift of the maximum of the $\mathrm{H}_{2} \mathrm{~S}$ release peak to lower temperatures.

$Y$ et, it is difficult to study the effect of the presence of a promoter on the rate of sulfiding as $\mathrm{Co}$ also influences the initial dispersion of the molybdenum oxide species. It was shown that on alumina the addition of $\mathrm{Co}$ (both coimpregnation and sequential impregnation) leads to an increase of the particle size of the molybdenum oxide species (32). It is expected that larger particles are more liable to sulfidation offering another explanation for the observed shift in the TPS pattern.

In contrast, the addition of $\mathrm{Co}$ to $\mathrm{Mo}_{\mathrm{O}} \mathrm{TiO}_{2}$ significantly lowers the sulfidation rate of $\mathrm{M} O$ as is clear from Fig. $5 \mathrm{C}$ and the TPS profile (Fig. 1). The lower sulfidation rate might be related to smaller molybdenum oxide particles in the promoted catalyst. Smaller particles are better stabilised by the titania surface and less susceptible to sulfidation. H owever, the particle size for both samples is not very different ( $\mathrm{N}_{\mathrm{M}_{0}-\mathrm{M}_{\mathrm{O}}}$ of 2.5 versus 1.8 ) and also the rapid decline of the 
M o-O contribution at $398 \mathrm{~K}$ for the promoted sample does not support this explanation. A possible explanation is formation of $\mathrm{COM} \mathrm{OO}_{4}$ on titania. From the former discussion for $\mathrm{Mo} / \mathrm{TiO}_{2}$ it became clear that the interaction between molybdenum oxide or its precursor and the titania surface is rather poor. This will favour the interaction of $\mathrm{Mo}$ with Co leading to $\mathrm{CoM} \mathrm{OO}_{4}$. $\mathrm{CoM} \mathrm{OO}_{4}$ is indeed known to sulfide at higher temperatures than $\mathrm{M} \mathrm{OO}_{3}(55)$, in agreement with our results. The very high values for the $\mathrm{M} \mathrm{O-S} \mathrm{coor-}$ dination number (up to 9 at $523 \mathrm{~K}$ ) and the absence of the $\mathrm{M}$ 0-O contribution are due to high structural disorder as discussed above for $\mathrm{M} \mathrm{O} / \mathrm{A} \mathrm{I}_{2} \mathrm{O}_{3}$.

$\mathrm{R}$ egarding the structure of the catalyst at $523 \mathrm{~K}$ the presence of a $\mathrm{M}$ o backscatterer at $2.73 \mathrm{~A}^{\circ}$ in $\mathrm{CoM}$ o/TiO 2 points to a dimer structure with bridging disulfide ligands like structure (B) in Fig. 9. Sulfidation at $673 \mathrm{~K}$ changes this structure directly into $\mathrm{M} \mathrm{OS}_{2}$ by reduction of the disulfide ligands. The absence of a $\mathrm{H}_{2} \mathrm{~S}$ release peak is due to sulfidation of the titania surface as for $\mathrm{M} \mathrm{o}_{\mathrm{TiO}}$.

\section{I nfluence of the M etal O xide-Support I nteraction}

A nalysis of the EX A FS data shows anchoring of M O clusters to the support via $\mathrm{M}-\mathrm{O}-\mathrm{X}(\mathrm{X}=\mathrm{A}$ I or $\mathrm{Ti})$ bondings with a M 0-O distance of $2.0 \AA^{\circ}$, as reported earlier (32). The current results indicate that these $\mathrm{M} 0-0-X$ linkages originate from the oxidic catalysts and partly remain throughout all stages of the sulfidation process.

Comparing the sulfidation of molybdenum supported on silica $(28,29)$, alumina, and titania reveals the influence of the support and particle size of the precursor on the intermediates. On silica the metal oxide support interaction is weak, resulting in rather large $\mathrm{M} \mathrm{OO}_{3}$ particles after calcination. These particles readily sulfide at low temperature to form most probably a $\mathrm{M} \mathrm{OS}_{3}$ bulk-like intermediate. The $\mathrm{M} \mathrm{OS}_{2}$ particles formed in reduction of $\mathrm{M} \mathrm{OS}_{3}$ are not bonded to the support and therefore are rather large $\left(\mathrm{N}_{\left.\mathrm{M}_{0}-\mathrm{M}_{\mathrm{O}}=4.7\right)}\right.$ (28). When bonded with the NTA complex the "M o" particles are smaller resulting in monomers and dimers as intermediates with $\mathrm{M} \mathrm{OS}_{3}$ features (29). The $\mathrm{M} \mathrm{OS}_{2}$ particles after

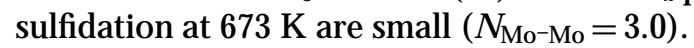

On alumina molybdenum oxide particles are well dispersed and more difficult to sulfide since they are bonded to the support. A s shown in this study, throughout the sulfidation processintermediate $\mathrm{M} \mathrm{OO}_{\mathrm{x}} \mathrm{S}_{\mathrm{y}}$ monomersand dimers remain in strong interaction with surface oxygen atoms and formed $\mathrm{M} \mathrm{OS}_{2}$ slabs are also fairly small $\left(\mathrm{N}_{\left.\mathrm{Mo}_{\mathrm{O}} \mathrm{M}_{\mathrm{o}}=2.9\right) . \mathrm{O}}\right.$ titania the initial dispersion of molybdenum oxide is less than on alumina which increases susceptibility to sulfidation. However, the better match between the titania surface structure and supported molybdenum sulfide clusters induces formation of only $\mathrm{M}$ o-sulfide monomers. The ultimate dispersion of the $\mathrm{M} \mathrm{OS}_{2}$ slabs is very high and a description as small molybdenum sulfide clusters rather than as $\mathrm{MoS}_{2}\left(\mathrm{~N}_{\mathrm{Mo}-\mathrm{Mo}}=0.5\right)$ is appropriate.
In conclusion a combination of initial dispersion of molybdenum oxide particles, predominantly controlled by the kind of support and the precursor, and the "match" between the surface of the support and formed intermediates both determine the structure of intermediates and the final $\mathrm{MoS}_{2}$ dispersion.

\section{CONCLUSIONS}

Thisstudy showed that the support influences the sulfidation of molybdenum oxide supported catalysts with respect to structural intermediates formed and the final dispersion of the $\mathrm{M} \mathrm{OS}_{2}$ slabs. A combination of initial dispersion of molybdenum oxide particles, influenced by the support and mode of preparation, and the "match" between the surface of the support and intermediates both determine the particle sizes of the molybdenum sulfide intermediates and the final $\mathrm{M} \mathrm{OS}_{2}$ slabs.

This study enabled us to describe the structure of the intermediates during sulfidation. B oth on alumina and titania all intermediates are anchored to the support via $\mathrm{M} \mathrm{0-O}$ bondings of $2.0 \mathrm{~A}^{\circ}$. I nitially, alumina oxysulfides are formed that are readily reduced to molybdenum sulfide monomers and dimers containing disulfide ligands. A bove $448 \mathrm{~K}$ the disulfide ligands are reduced with hydrogen to yield molybdenum sulfide dimers with a Mo-Mo distance of $2.77 \AA$. A bove $523 \mathrm{~K}$ these dimers aggregate to $\mathrm{MoS}_{2}$ particles. Titania molybdenum oxide particles are sulfided to yield molybdenum sulfide monomers at $523 \mathrm{~K}$, which also aggregate to $\mathrm{M} \mathrm{OS}_{2}$ at higher sulfidation temperatures.

The addition of $\mathrm{Co}$ to $\mathrm{M}$ o/alumina has no effect on the kind of intermediates formed during sulfidation. H owever, the rate of the sulfidation as indicated by the TPS profile is increased. On titania the promotion of Mo with $\mathrm{Co}$ has a pronounced effect. The rate of sulfidation is considerably lower, due to the formation of $\mathrm{CoM} 0 \mathrm{O}_{4}$ during preparation, that is less susceptible to sulfidation.

\section{ACK NOW LED GMENTS}

B arbara $\mathrm{M}$ ojet and $\mathrm{G}$ ert van D orssen are acknowledged for their assistance at the SR S in D aresbury. A kzo-N obel R esearch Center A msterdam is gratefully acknowledged for the financial support.

\section{REFERENCES}

1. M assoth, F. E ., A dv. Catal. 27, 265 (1978).

2. G ates, B. C., K atzer, J. R ., and Schuit, G. C. A ., "Chemistry of Catalytic Processes." M cG raw-H ill, N ew York, 1979.

3. R atnasamy, P., and Sivasanker, S., C atal. R ev.-Sci. E ng. 22, 401 (1980).

4. G range, P., Catal. R ev.-Sci. E ng. 21, 135 (1980).

5. Keely, W. M., Jerus, P., D ienes, E. K., and H ausberger, A . L., Catal. Rev.-Sci. Eng. 26, 485 (1984).

6. D ellanay, F., A ppl. Catal. 16, 135 (1985).

7. Topsøe, H., Clausen, B. S., Topsøe, N. Y., and Pedersen, E., Ind. Eng. Chem. Fund. 25, 25 (1986). 
8. Topsøe, H ., Clausen, B. S., A ppl. Catal. 25, 273 (1986).

9. Prins, R ., de B eer, V. H. J., and Somorjai, G. A ., Catal. R ev.-Sci. Eng. 31, 1 (1989).

10. Luck, F., Bull. Soc. Chim. B elg. 100, 781 (1991).

11. Breysse, M., Portefaix, J. L., and V rinat, M., Catal. Today 10, 489 (1991).

12. Delmon, B., Catal. L ett. 22, 1 (1993).

13. Chianelli, R. R., D aage, M., and Ledoux, M. J., A dv. Catal. 40, 177 (1994).

14. Startsev, A. N., Catal. R ev.-Sci. Eng. 37, 353 (1995).

15. B ouwens, S. M . A . M ., Prins, R ., de B eer, V. H . J., and Koningsberger, D. C., J. Phys. Chem. 94, 3711 (1990).

16. B ouwens, S. M. A . M ., van Veen, J. A. R., Koningsberger, D. C., de B eer, V. H. J., and Prins, R., J. Phys. Chem. 95, 123 (1991).

17. Bouwens, S. M. A. M., van Zon, F. B. M., van Dijk, M. P., van der K raan, A . M ., de B eer, V. H . J., van Veen, J. A . R ., and K oningsberger, D. C., J. Phys. Chem. 146, 375 (1994).

18. Crajé, M. W. J., de B eer, V. H. J., and van der K raan, A . M ., B ull. Soc. Chim. B elg. 100, 953 (1991).

19. Crajé, M. W. J., de Beer, V. H. J., and van der Kraan, A. M., A ppl. Catal. 70, L 7 (1991).

20. H allie, H., O il G as J. 80, 69 (1982).

21. Scheffer, B., de Jonge, J. C. M., A rnoldy, P., and M oulijn, J. A ., B ull. Soc. Chim. B elg. 93, 751 (1984).

22. A rnoldy, P., van den Heijkant, J. A. M., de Bok, G. D., and Moulijn, J. A., J. Catal. 92, 35 (1985).

23. M angus, P. J., Poels, E. K ., and M oulijn, J. A ., Ind. E ng. Chem. Res. 32, 1818 (1993).

24. Schrader, G. L., and Cheng, C. P., J. Catal. 80, 369 (1983).

25. Payen, E ., K asztelan, S., H oussenbay, S., Szymanski, R ., and G rimblot, J., J. P hys. Chem. 93, 6501 (1989).

26. Parham, T. G., and M erill, R. P., J. Catal. 85, 295 (1984).

27. Chiu, N-S., Bauer, S. H., and Johnson, M. F. L., J. Catal. 98, 32 (1986).

28. de Boer, M ., van Dillen, A . J., Koningsberger, D. C., and G eus, J. W., J. P hys. Chem. 98, 7862 (1994).

29. M edici, L., and Prins, R ., J. Catal. 163, 38 (1996).

30. de Jong, A . M ., B org, H. J., van Ijzerdoorn, L. J., Soudant, V. G. F. M ., de Beer, V. H. J., van Veen, J. A. R., and Niemandsverdriet, J. W., J. Phys. Chem. 97, 6477 (1993).

31. Muijsers, J. C., Weber, Th., van Hardeveld, R. M., Zandbergen, H. W., and Niemandsverdriet, J. W., J. Catal. 157, 698 (1995).
32. Leliveld, R. G., Van Dillen, A. J., Geus, J. W., and Koningsberger, D. C., J. Catal. 165, 184 (1997).

33. Vaarkamp, M., M ojet, B. L., Kappers, M. J., Miller, J. T., and Koningsberger, D. C., J. P hys. Chem. 99, 16067 (1995).

34. Van Zon, J. B. A. D., Koningsberger, D. C., Van Blik, H. F. J., and Sayers, D. E., J. Chem. Phys. 82, 5742 (1985).

35. B ouwens, S. M . A . M ., Prins, R ., de B eer, V. H . J., and Koningsberger, D. C., J. Phys. Chem. 94, 3711 (1990).

36. M ustre de L eon, J., R ehr, J. J., and Zabinsky, S. I., Phys. Rev. B 44, 4146 (1991).

37. D uivenoorden, F. B. M ., Koningsberger, D. C., U h, Y. S., and G ates, B. C., J. A m. Chem. Soc. 108, 6524 (1986).

38. Kampers, F. W. H., Engelen, C. W. R., Van Hooff, J. H. C., and Koningsberger, D. C., J. P hys. Chem. 94, 8574 (1990).

39. Lytle, F. W., Sayers, D. E ., and Stern, E . A ., P hysica B 158, 701 (1988).

40. Stern, E ., N ewville, M ., R avel, B., Y acoby, Y ., and H askel, D., P hysica B 208/209, 117 (1995).

41. Kutzler, F. W., N atoli, C. R ., M isemer, D. K ., D oniach, S., and H odgson, K. O., J. Phys. Chem. 73, 3274 (1980).

42. M ensch, C. T. J., van Veen, J. A . R ., van Wingerden, B., and van Dijk, M. P., J. Phys. Chem. 92, 4961 (1988).

43. Teo, B-K., and Lee, P. A ., J. A m. Chem. Soc. 101, 2815 (1979).

44. B aes, C. F., and M esmer, R. E., "The H ydrolysis of Cation," Wiley, New York, 1976.

45. van Veen, J. A. R., Hendriks, P. A . J. M., Romers, E. J. G. M., and A ndrea, R. R., J. Phys. Chem. 94, 5275 (1990).

46. Weber, Th., M uijsers, J. C., van Wolput, J. H. M. C., Verhagen, C. P. J., and N iemandsverdriet, J. W., J. P hys. Chem. 100, 14144 (1996).

47. Cohen, S. A ., and Stiefel, E . I., O rganomet. 4, 1689 (1985).

48. Chien, F. Z., M oss, S. C., Liang, K. S., and Chianelli, R. R ., P hys. Rev. B 29, 4606 (1984).

49. H ibble, S. J., R ice, D. A ., Pickup, D. M ., and B eer, M. P., Inorg. Chem. 34, 5109 (1995).

50. Weber, Th., M uijsers, J. C., and N iemandsverdriet, J. W., J. P hys. Chem. 99, 9194 (1995).

51. D iemann, E ., Weber, Th., and M üller, A ., J. Catal. 148, 288 (1994).

52. M üller, B., van L angeveld, A . D., M oulijn, J. A ., and K nözinger, H ., J. Phys. Chem. 97, 9028 (1993).

53. H uisman, H. M., Ph.D. thesis, U niversity of U trecht, 1994.

54. Scheffer, B., de Jonge, J. C. M., A rnoldy, P., and M oulijn, J. A ., Bull. Soc. Chim. Belg. 93, 751 (1984).

55. de B oer, M., Ph.D. thesis, U trecht U niversity, 1992. 